\title{
Creep Rupture Properties of Ti-8Al-1Mo-1V Alloy
}

\author{
W. D. Jenkins and W. A. Willard \\ Institute for Materials Research, National Bureau of Standards, Washington, D.C. 20234
}

(November 22, 1967)

\begin{abstract}
Creep tests were made at $600,800,1000$, and $1200{ }^{\circ} \mathrm{F}\left(588,699,811\right.$, and $\left.921^{\circ} \mathrm{K}\right)$ on duplex-annealed Ti-8Al-1Mo-1V alloy specimens. Creep-test conditions were selected to produce creep rates ranging from 0.1 to 50,000 percent per 1,000 hours and rupture times ranging from 0.1 to about 10,000 hours. Conformance of the test data to creep theories was obtained over a limited range of stress, strain, creep rate and temperature. Creep behavior was influenced by microstructural changes during creep and by prior thermal-mechanical treatment. Engineering-design curves are included in this paper.
\end{abstract}

Key Words: Creep, engineering design, high temperatures, phase changes, rupture, titanium alloy.

\section{Introduction}

During the past several years a comprehensive program has been in progress at the National Bureau of Standards to evaluate factors influencing the mechanical behavior of metals at elevated temperatures. Concurrent with the presentation of engineering data, obtained in tensile and creep tests made on a variety of metals, the mechanical properties were interpreted in terms of modern theories of plastic deformation. The validity of most of the theories were confined to a limited range of variables. As the status of current theory of creep behavior is well documented $[1,2],{ }^{1}$ an effort will be made in the present paper to omit the derivations of the formulas and to apply only those concepts pertinent to the data obtained on a titanium alloy. The variables considered here are stress, temperature, creep rate, ductility, rupture time, microstructural changes, and prior strain history. Results are presented for creep tests made on the alpha-beta duplexannealed alloy, Ti-8Al-1Mo- $1 \mathrm{~V}$, at temperatures of $600,800,1000$, and $1200^{\circ} \mathrm{F}\left(588,699,811\right.$, and $\left.921^{\circ} \mathrm{K}\right)$.

\section{Material and Testing Procedure}

The titanium alloy, Ti-8Al-1Mo-1V, selected for this investigation is one of the structural materials intended for use in supersonic transport aircraft.

The test specimens were prepared from bars obtained from the same heat as that used in a previous research program to evaluate the effects of notch geometry on the tensile behavior of this alloy [3].

\footnotetext{
${ }^{1}$ Figures in brackets indicate the literature references at the end of this paper.
}

The bars were supplied by the manufacturer in the form of 1-in rounds in the hot-rolled and annealed condition. The chemical composition of the alloy is given in table 1.

TABLE 1. Chemical composition (percentage by
weight) of the alloy used

\begin{tabular}{|c|c|}
\hline Titanium. & 90.4 \\
\hline Aluminum & 7.7 \\
\hline Molybdenum.. & 1.0 \\
\hline Vanadium................. & 0.7 \\
\hline Iron........... & .08 \\
\hline Carbon.... & .01 \\
\hline Hydrogen.......... & .0094 \\
\hline Oxygen...................... & .0628 \\
\hline Nitrogen...................................... & .0022 \\
\hline
\end{tabular}

a Analysis made at the National Bureau of Standards.

The bars were cut into lengths, each about 6.5 -in and annealed at $1750{ }^{\circ} \mathrm{F}\left(1226^{\circ} \mathrm{K}\right)$ for $\mathrm{l} \mathrm{hr}$ and aircooled. This was followed by a stabilizing anneal for $8 \mathrm{hr}$ at $1050{ }^{\circ} \mathrm{F}\left(838{ }^{\circ} \mathrm{K}\right)$. The specimens were then air-cooled. This process, called duplex-annealing, is recommended for obtaining a good combination of properties at high temperatures.

Each unnotched specimen had a 2-in gage length and a gage diameter of $0.357 \mathrm{in}$. The reduced section was finished by grinding and polishing the axial direction.

Before testing, each creep specimen was heated in a tube furnace to the desired temperature and equilibrated at temperature for $16 \mathrm{hr}$. It was then tested at temperature under constant load. The creep-rupture machines used were of a multiple lever type with 
motorized jacks to prevent shock loading. They had been calibrated at room temperature and the errors for the stresses used were less than 0.5 percent. The temperature of each of the specimens was controlled to an accuracy of $\pm 2{ }^{\circ} \mathrm{F}$. Strain-time data were obtained from electric contact follow-up type extensometers attached to shoulders of the specimens. The sensitivity of extension measurement was approximately $0.00005 \mathrm{in}$. Metallographic examinations were made on specimens after fracturing in creep to assess the influence of the test variables on changes in microstructure.

In order to permit selection of creep stresses to be used in this investigation, short-time tensile tests were made in duplicate at the same temperatures as those later used in the creep tests. The average tensile values are shown in table 2.

TABLE 2. Short time tensile properties of the duplex-annealed alloy

\begin{tabular}{c|c|c|c|c}
\hline \hline $\begin{array}{c}\text { Temper- } \\
\text { ature }\end{array}$ & $\begin{array}{c}\text { Yield } \\
\text { strength, } \\
0.2 \% \\
\text { offset }\end{array}$ & $\begin{array}{c}\text { Tensile } \\
\text { strength }\end{array}$ & Elongation & $\begin{array}{c}\text { Reduction } \\
\text { of area }\end{array}$ \\
\hline${ }^{\circ} F$ & $K s i$ & $K s i$ & $\%$ & $\%$ \\
75 & 135 & 144 & 22 & 32 \\
600 & 87 & 110 & 21 & 43 \\
800 & 80 & 98 & 27 & 52 \\
1000 & 65 & 76 & 41 & 77 \\
1200 & 45 & 51 & 82 & 86 \\
\hline
\end{tabular}

\section{Results and Discussion}

\subsection{Creep Test Data}

Extension-time data were plotted on a linear scale for all the specimens tested under various conditions (not shown). All the curves produced in this manner had the same general shape in that the first, second, and third stages of creep were clearly discernible. Loci of beginning of the third stage of creep, loci of fracture, and second stage creep rates were determined from these curves. However, no simple translation process could make the curves coincide for tests made at the same temperatures with different stresses or at different temperatures with equal stresses. J. deLacomb [4] has suggested that creep curves of this type could be described by the sum of two parabolic curves. Thus,

$$
\epsilon=\epsilon_{0}+a t^{m}+b t^{n}
$$

where

$$
\begin{aligned}
& \epsilon=\text { creep strain } \\
& \epsilon_{0}=\text { instantaneous strain } \\
& t=\text { time } \\
& a \text { and } b=\text { constants } \\
& m<1 \text { and } n>1 .
\end{aligned}
$$

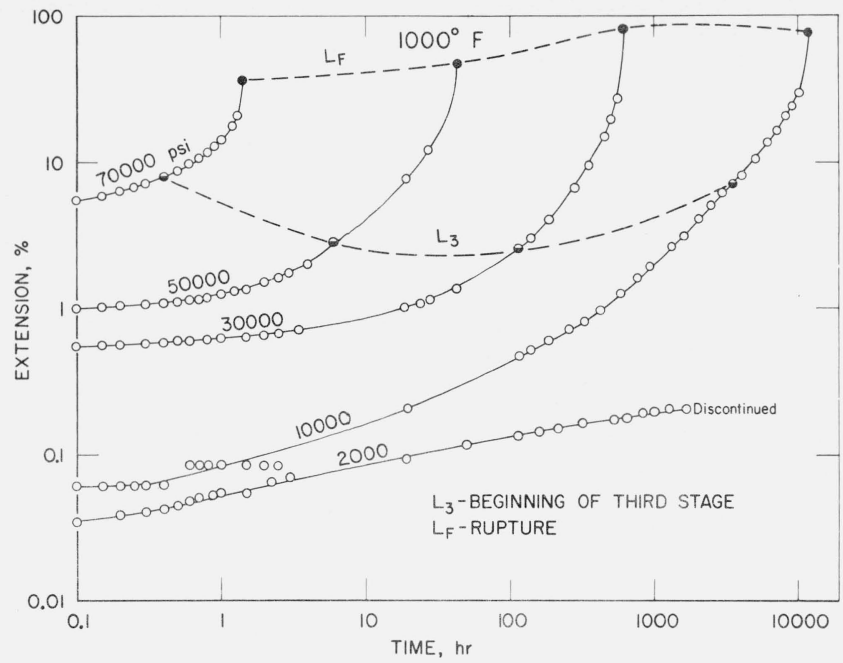

FigURE 1. Extension-time relations for specimens tested at $1000^{\circ} \mathrm{F}$.

Extension-time curves for specimens tested at 1000 and $1200{ }^{\circ} \mathrm{F}$ in the present investigation are shown in figures 1 and 2. These data, as plotted on a log-log scale, indicate a qualitative conformance to eq (1) only over limited ranges of time if $\epsilon_{0}$ is considered to be equal to zero. However, from a design engineering standpoint, the $0.1 \mathrm{hr}$ and also the subsequent extensions are readily observable. Moreover, the loci of the beginning of the third stage indicate a minimum a) $1000{ }^{\circ} \mathrm{F}$, whereas both a minimum and maximum ase present at $1200{ }^{\circ} \mathrm{F}$. The loci of fracture at each temperature are quite similar in shape.

A number of formulas have be derived, empirically and theoretically, describing the dependence of second-stage creep rate or fracture time on creep stress $[1,2]$. Generally, it has been found that at

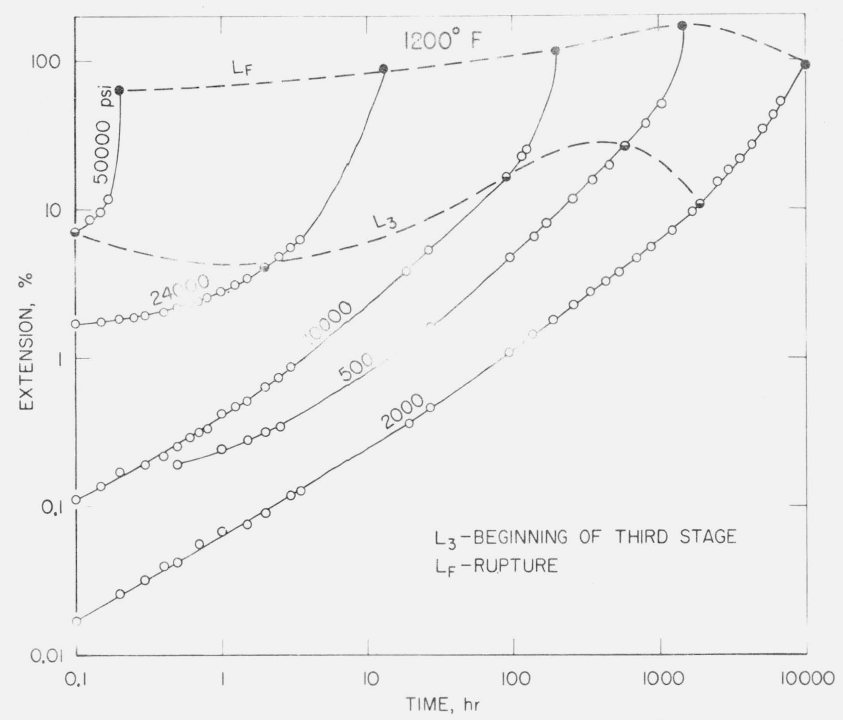

FIGURE 2. Extension-time relations for specimens tested at $1200^{\circ} \mathrm{F}$. 


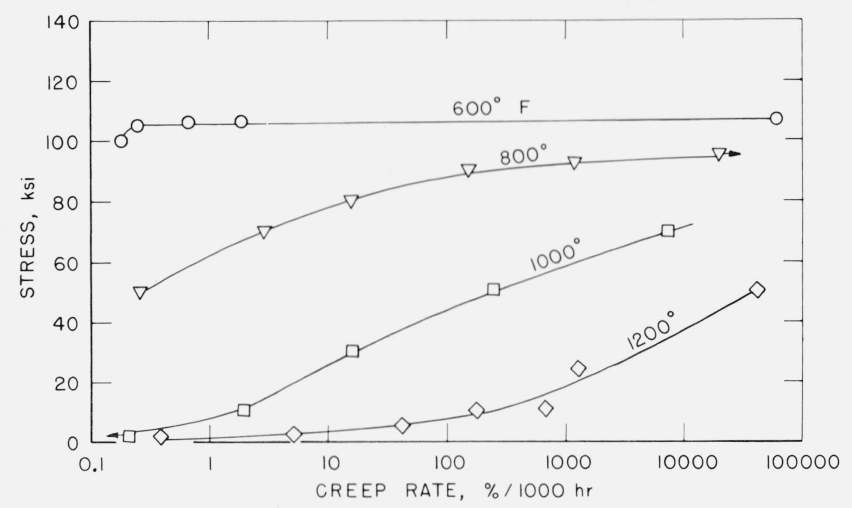

FIGURE 3. Effect of stress on second-stage creep rate of specimens tested at different temperatures.

"low" stresses and "high" temperatures the stress dependence is given by

$$
\dot{\epsilon}_{s}=A \sigma^{n}
$$

or

$$
t_{r}=A_{1} \sigma^{-n_{1}}
$$

where

$$
\begin{aligned}
& \dot{\epsilon}_{s}=\text { second stage creep rate } \\
& t_{r}=\text { rupture time } \\
& \sigma=\text { creep stress } \\
& n, n_{1}, A, B, A_{1} \text {, and } B_{1}=\text { constants which }
\end{aligned}
$$

are dependent on temperature.

$$
\dot{\epsilon}_{s}=A \exp (B \sigma)
$$

and

$$
t_{r}=A_{1} \exp \left(-B_{1} \sigma\right) \text {. }
$$

However, at "high" stresses and "low" temperatures the stress dependence is given by the formula first proposed by Kanter [5]. Equations (3) and (3a) indicate that there should be a linear relation between stress and either log second stage creep rate or log rupture time. Data obtained on the Ti-8Al-1Mo-1V specimens are plotted as a function of stress in figures 3 and 4 . Although the equations indicate that in each of these sets the two curves should be mirror

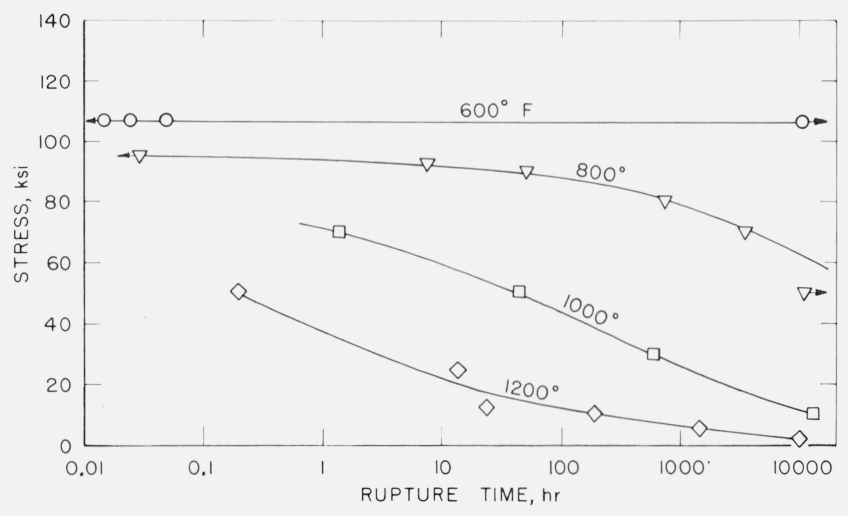

FIGURE 4. Effect of stress on rupture time of specimens tested at different temperatures. images of each other, quantitative evaluation of the data showed that, at each temperature, the slopes of $\log t_{r}$ versus $\epsilon_{s}$ curves (not shown) were different at each temperature and at each stress level. This observation indicated that the mechanism of deformation at these temperatures is different as the test parameters are changed. However, the curves in figures 3 and 4 do show that the strength of the alloy is more rate-sensitive at the higher temperatures than at the lower temperatures. Additionally, the rate-sensitivity at the different stress levels is an inconsistent index of the creep behavior of the metal.

The variation of stress with temperature to produce engineering-design curves (A) rupture at various times and (B) various second-stage creep rates is shown in figure 5. The data are derived from figures 3 and 4 . The shape of these curves indicates the dangers of predicting behavior of metals for long-time service from data obtained in short-time tests. In addition, the slopes of these stress-temperature curves indicate continuously changing mechanisms of deformation and fracture at the different temperatures. The similarity of families of curves of the type shown in figures $5 \mathrm{~A}$ and 5B led Monkman and Grant [6] to propose a relation of the form

or

$$
t_{r}=K \dot{\epsilon}_{s}^{-m_{1}}
$$

$$
\log t_{r}=m_{1} \log \dot{\epsilon}_{s}+\log K
$$

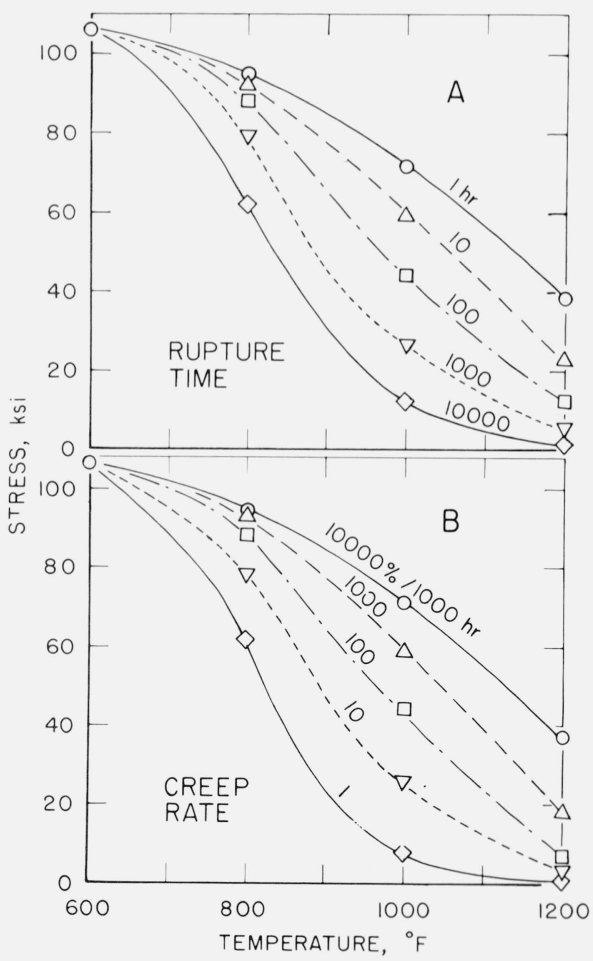

FigURE 5. Variation of stress with temperature required to $(A)$ cause rupture at various times and $(B)$ produce various second stage creep rates. 


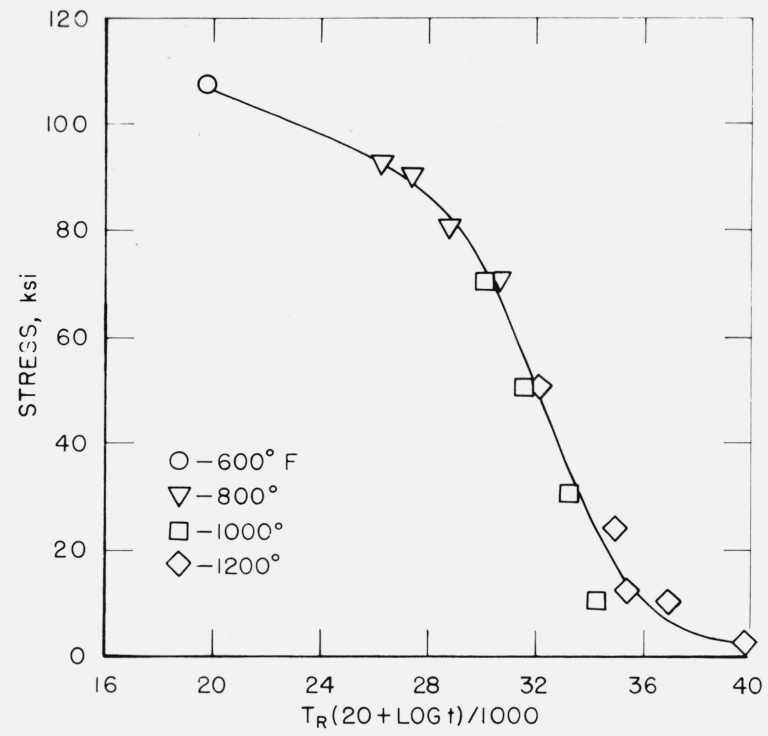

FIGURE 6. Relation between creep stress and Larson-Miller parameter.

$T_{R}=$ Temperature in degrees Rankine

$t=$ Rupture time in hours.

where

$$
\begin{aligned}
t_{r} & =\text { rupture time } \\
\epsilon_{s} & =\text { second stage creep rate } \\
m_{1} & =\text { slope of } \log \epsilon_{s} \text { versus } \log t_{r} \\
K & =\text { constant. }
\end{aligned}
$$

However, a plot of the product $\left(t_{r} \dot{\epsilon}_{s}\right)$ versus temperature did not yield straight lines for the data in this investigation.

A number of methods have been used for extrapolation of creep data by use of parametric formulas [1]. A time-temperature parameter derived by Larson and Miller [7] and based on the general Arrhenius rate equation is of the form

where

$$
P_{t}=f(\sigma)=T_{R}\left(\log t+A_{4}\right)
$$

$$
\begin{aligned}
P_{t} & =\text { parameter } \\
\sigma & =\text { stress } \\
T_{R} & =\text { temperature in degrees Rankine } \\
t & =\text { rupture time } \\
A_{4} & =\text { constant (generally } 20 \text { ). }
\end{aligned}
$$

Conformance of the present data to this expression is shown in figure 6. Although a single curve can be roughly drawn through the experimental points, it is impossible to predict in advance the shape of this curve. Until some parametric expression can be derived which will include metallurgical changes affecting ductility at the different temperatures, these formulas will be considered useful only for cataloging engineering data.

Most theoretical analyses of creep phenomena indicate that there should be a continuous change in rupture ductility values with changes in stress or rupture

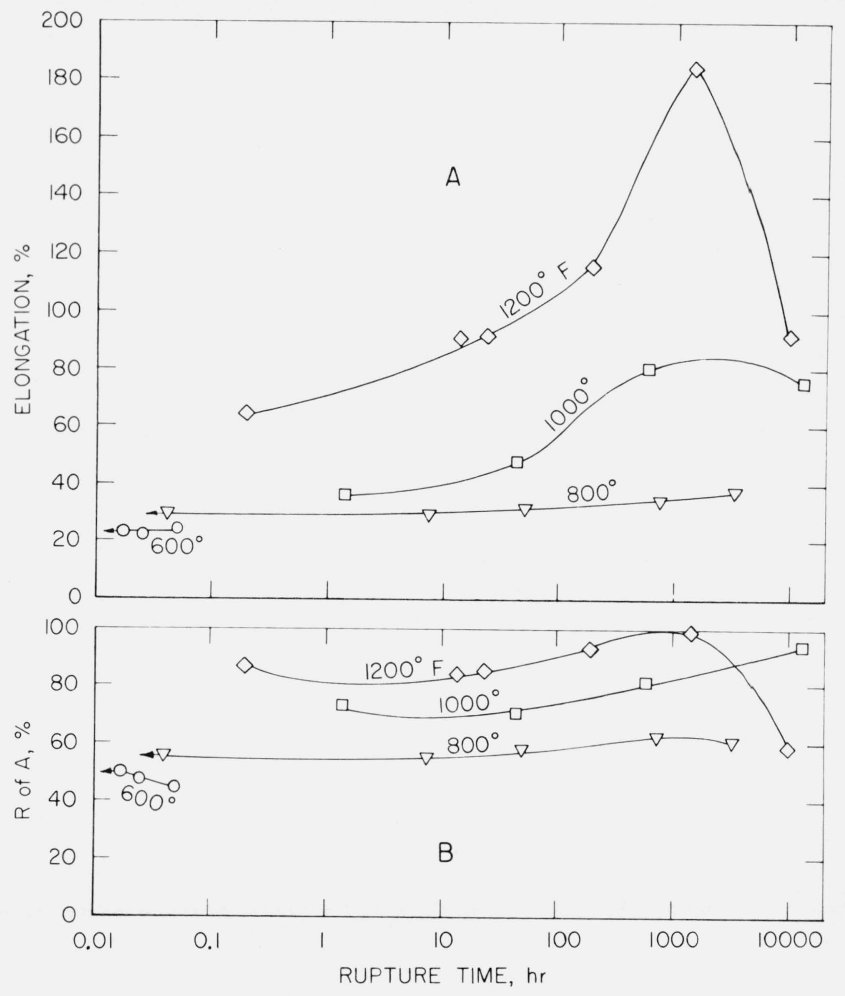

FIGURE 7. Effect of test time on elongation and reduction of area values for specimens ruptured at different temperatures.

time. Examples in the literature have shown that the validity of this concept is often affected by precipitation [8], recrystallization [9], grain boundary weakening [10] and other metallurgical phenomena. The relation between rupture-time and elongation and reduction of area values of the titanium alloy specimens used in the present investigation is shown in figure 7 . Anomalies in the curves may be attributed to recovery, internal cracking, and the dissolution of the beta phase during the long-time tests.

The interrelationship of of the variables associated with creep testing [1] generally presupposes the existence of an equation of state for creep of the general form

$$
\sigma=f\left(\dot{\epsilon}_{s}, T, \epsilon\right)
$$

or

$$
\sigma=f_{1}\left(t_{r}, T, \epsilon\right)
$$

where

$$
\begin{aligned}
\sigma & =\text { creep stress } \\
\epsilon_{s} & =\text { creep rate } \\
T & =\text { absolute temperature } \\
\epsilon & =\text { strain } \\
t_{r} & =\text { rupture time. }
\end{aligned}
$$

These equations indicate that creep behavior is independent of the prior thermal-mechanical history of the metal. This is not borne out by figure 8 , which shows the effect of prior history on the subsequent 


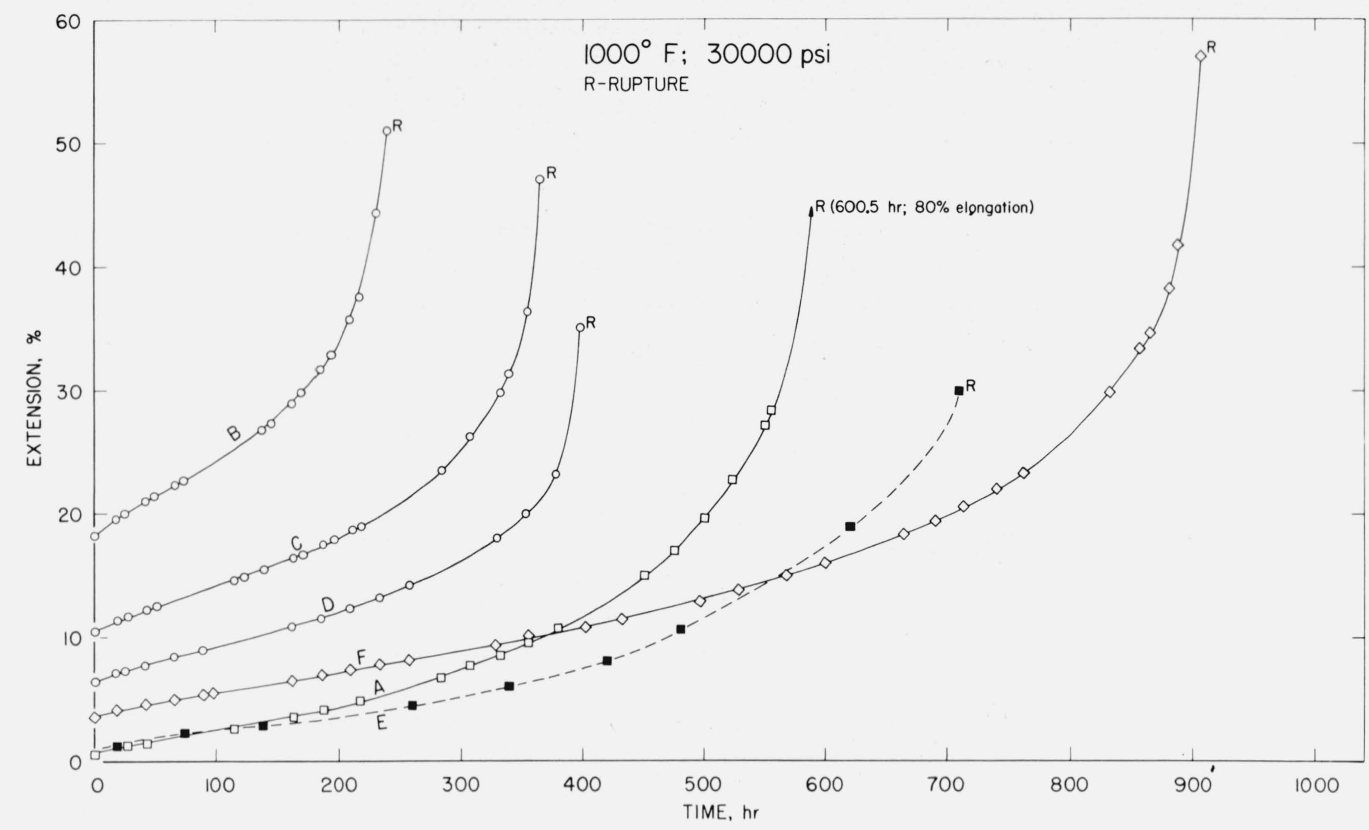

FIGURE 8. Effect of prior strain history on extension-time relations for specimens tested at $1000^{\circ} \mathrm{F}$ with a stress of $30,000 \mathrm{psi}$.

\begin{tabular}{|c|c|c|c|c|}
\hline \multirow{2}{*}{ Curve } & \multirow{2}{*}{$\begin{array}{c}\text { Specimen } \\
\text { No. }\end{array}$} & \multicolumn{3}{|c|}{ Pre-strain history } \\
\hline & & Temperature & Time & Extension \\
\hline & & ${ }^{\circ} \mathrm{F}$ & $h r$ & $\%$ \\
\hline A.. & 28 & None & None & None \\
\hline B.. & 29 & 600 & 866 & \\
\hline C. & 9 & 600 & 7003 & 10.5 \\
\hline D. & 11 & 600 & 837 & 4.7 \\
\hline E. & 33 & 1000 & 1655 & 0.21 \\
\hline & 34 & 1200 & 5301 & 3.5 \\
\hline
\end{tabular}

strain-time relations of specimens tested in this investigation at $1000{ }^{\circ} \mathrm{F}$ with a stress of 30,000 psi. The extension values are the total extensions obtained during testing under each condition; the stress value is based on the original cross-sectional areas; and the time is the time at $1000{ }^{\circ} \mathrm{F}$ and 30,000 psi only. At all temperatures within the limits of this investigation, prior creep decreased the elongation at rupture. However, the rupture time was increased with increase in the temperature at which the specimens were deformed. Although prior thermal history was an inconsistent index of the elongation values, it appears that increasing the prior extension at constant temperature (curves D, C, and B) caused a decrease in the elongation values. Within the range of temperatures used these data prove conclusively that the creep behavior of this titanium alloy is strongly dependent on its thermal-mechanical history.

\subsection{Metaliography}

Photographs and micrographs of selected specimens after rupture in creep are shown in figures 9 through 13.

Surface appearances of some of the creep specimens are shown in figure 9. The surface of a specimen prestrained in creep at $600{ }^{\circ} \mathrm{F}$ (fig. 9B) before creep testing at $1000{ }^{\circ} \mathrm{F}$ with a stress of 30,000 psi was approximately the same as that of a specimen completely tested at $1000^{\circ} \mathrm{F}$ with the same stress (fig. 9A). Extensive cracking was observed on the surface of the specimen pretested at $1200{ }^{\circ} \mathrm{F}$ (fig. 9C). However, the ductility of this specimen was no more seriously affected by these cracks than the one prestrained at $600{ }^{\circ} \mathrm{F}$. Surface cracks were also observed on a specimen creep-tested for a long time (fig. 9D) at $1000^{\circ} \mathrm{F}$ even though the reduction of area was greater for this specimen than for the one tested for a relatively short time (fig. 9A). Apparently, a different deformation mechanism contributed to increase ductility and counteracted the embrittling effects of surface cracking. This observation is also evident when the surface conditions of two specimens tested at $1200{ }^{\circ} \mathrm{F}$ for a short time (fig. 9E) and a long time (fig. 9F) are compared.

The number, size and shape of cracks near the main fracture was affected by temperature, prior strain history, and rupture time as shown in figure 10 . Elliptical holes, associated with low temperature deformation, are evident in figure $10 \mathrm{~A}$. As the tem- 


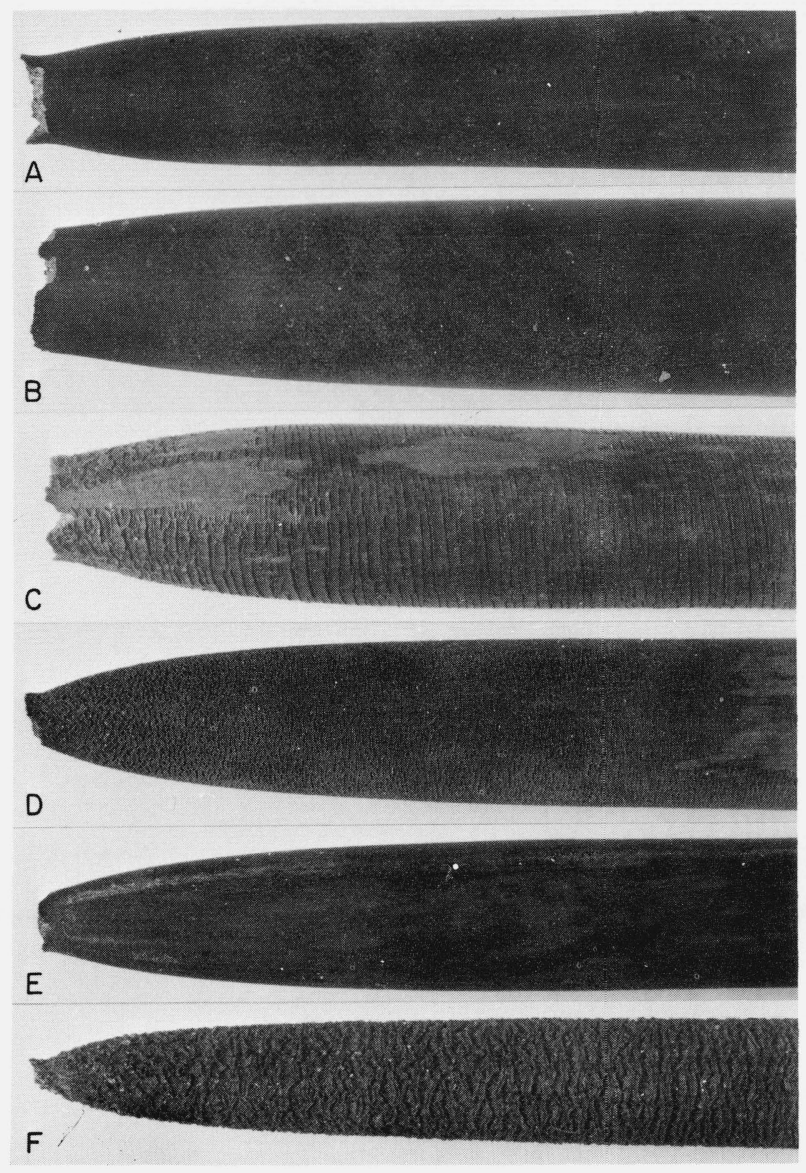

FIGURE 9. Photographs of specimens after rupture in creep. $\times 5$.

\begin{tabular}{|c|c|c|c|c|c|c|c|}
\hline \multirow{2}{*}{\multicolumn{2}{|c|}{ Temperature }} & \multirow{2}{*}{$\begin{array}{l}\text { Rupture } \\
\text { time }\end{array}$} & \multirow{2}{*}{$\begin{array}{c}\text { Elonga- } \\
\text { tion }\end{array}$} & \multirow{2}{*}{$\begin{array}{c}\text { Reduction } \\
\text { of area }\end{array}$} & \multicolumn{3}{|c|}{ Prestrain history } \\
\hline & & & & & Temperature & Time & Extension \\
\hline $\begin{array}{l}\text { A } \\
\text { B } \\
\text { C } \\
\text { D } \\
\text { E } \\
\text { F }\end{array}$ & $\begin{array}{l}{ }^{\circ} F \\
1000 \\
1000 \\
1000 \\
1000 \\
1200 \\
1200\end{array}$ & \begin{tabular}{r}
\multicolumn{1}{c}{$h r$} \\
601 \\
240 \\
907 \\
13009 \\
195 \\
1450
\end{tabular} & $\begin{array}{l}\% \\
80 \\
51 \\
57 \\
73.5 \\
115 \\
184\end{array}$ & $\begin{array}{ll}\% & \\
81 \\
71 \\
70 \\
94 \\
93 \\
99\end{array}$ & $\begin{array}{l}{ }^{\circ} F \\
\text { None } \\
600 \\
1200 \\
\text { None } \\
\text { do. } \\
\text { do. }\end{array}$ & $\begin{array}{l}\quad h r \\
\text { None } \\
866 \\
5300 \\
\text { None } \\
\text { do. } \\
\text { do. }\end{array}$ & $\begin{array}{c}\% \\
\text { None } \\
17 \\
3.5 \\
\text { None } \\
\text { Do. } \\
\text { Do. }\end{array}$ \\
\hline
\end{tabular}

perature is raised, fewer internal cracks and holes were observed (fig. 10C) and even fewer were evident as the test time was increased (fig. 10D). Additionally, the flow and fracture mechanisms associated with prestraining at $600^{\circ} \mathrm{F}$ (fig. 10B) contributed to the microcracking and decreased ductility of this specimen.

As shown previously (3), microstructure of the duplex-annealed alloy indicated the presence of equiaxed grains and lamellae of the beta phase in the alpha matrix. These microstructures were still evident in specimens tested to rupture at $600{ }^{\circ} \mathrm{F}$ (fig. $11 \mathrm{~A}$ and B) but they were more evident in regions away from complete fracture (fig. 11B) than in regions near fracture (11A). As the test temperature was raised to $1000^{\circ} \mathrm{F}$, less lamellar structure was evident as shown in figures $11 \mathrm{C}$ and $\mathrm{D}$. The presence of beta is associated both with a strengthening effect and a decrease in ductility of the specimens. Moreover, cracking generally occurred in the regions of the alpha grain boundaries and was never observed in the regions having a lamellar structure.

As shown in figure 12 , cracks at alpha grain boundaries, less distinct grain boundaries, and appreciable lessening of beta is more evident as the test temperature was increased to $1200{ }^{\circ} \mathrm{F}$. The increase in elongation from 90 to 184 percent may be attributed to both recovery and the dissolution of beta into alpha during creep.

Effect of prior strain history on microstructure is shown in figure 13. Grain boundaries are less distinct and the amount of intercrystalline cracking is decreased as the prestraining temperature was increased. 


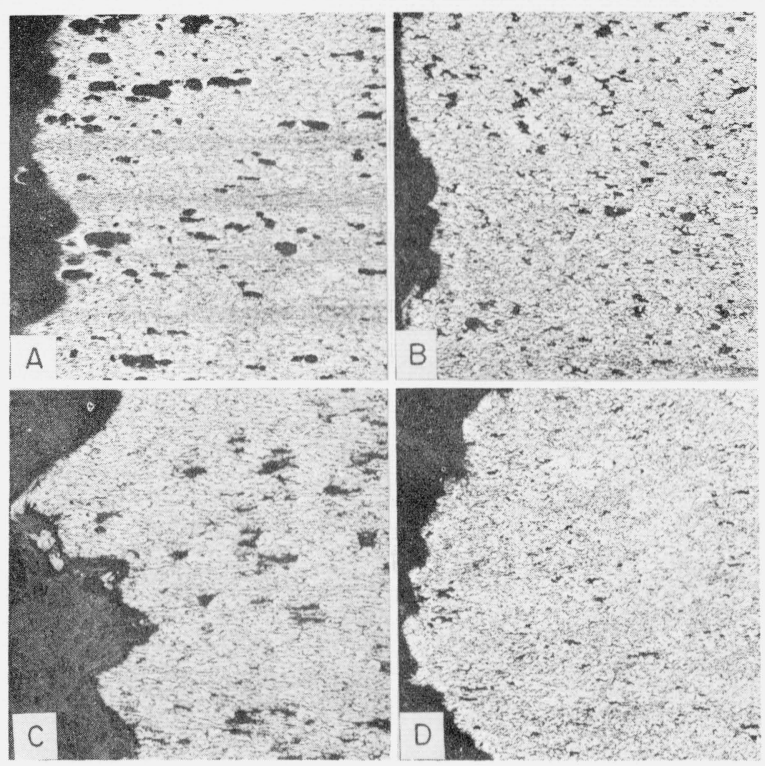

FIGURE 10. Microstructures of specimens near axis near fracture. $\times 100$.

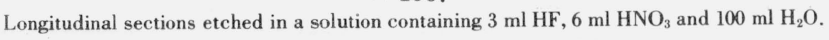

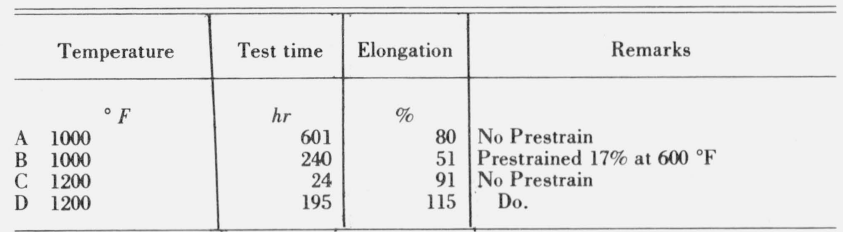

These two factors are consistent indices of the rupture life at this temperature and stress, as it was previously shown (fig. 8) that the rupture life increased with increase in prestrain temperature.

\section{Summary}

Creep tests were made on duplex-annealed Ti-8Al$1 \mathrm{Mo}-1 \mathrm{~V}$ alloy specimens at temperatures of 600,800 , 1000 , and $1200^{\circ} \mathrm{F}$.

Creep stresses were used to produce second stage creep rates ranging from 0.1 to 50,000 percent per $1,000 \mathrm{hr}$ and rupture times ranging from 0.1 to about $10,000 \mathrm{hr}$.

Conformance of the data to theoretical concepts is limited to small ranges of temperature and stress. This lack of agreement is attributed to the type of deformation, recovery, extent of cracking, phase transformation and prior thermal-mechanical history.

Ductility at fracture generally increased with increase in temperature but varied inconsistently with test time.

Rupture time increased with increase in prestraining temperature and, at constant temperature, with decrease in the amount of prestraining.

More cracks at the surface than in the interior were

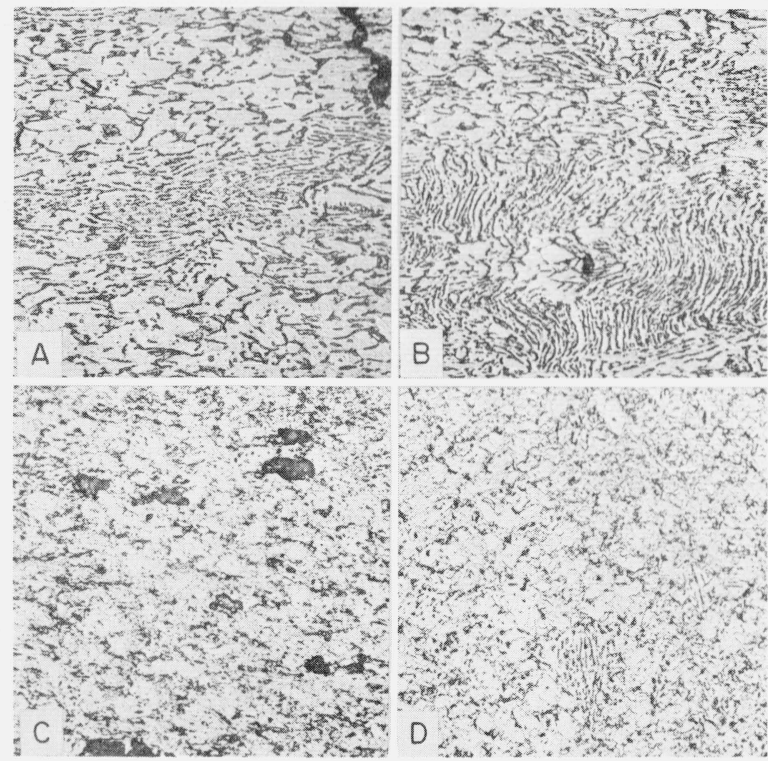

FIGURE 11. Effect of test temperature on microstructures of specimens after rupture in creep. $\times 500$.

Longitudinal sections, etched in a solution containing $3 \mathrm{ml} \mathrm{HF}, 6 \mathrm{ml} \mathrm{HNO}$, and $100 \mathrm{ml} \mathrm{H}_{2} \mathrm{O}$.

\begin{tabular}{lr|r|l}
\hline \hline & & & \\
& Temperature & Elongation & \multicolumn{1}{|c}{ Remarks } \\
\hline & & $\%$ & \\
A & 600 & & \\
B & 600 & 24 & Near fracture \\
C 1000 & 24 & Same specimen as A; 0.2 in from fracture \\
D 1000 & 75 & Near fracture \\
\hline
\end{tabular}

observed in specimens tested at high temperatures and slow creep rates, whereas there were fewer cracks in the interior of the specimens ruptured at the high temperatures.

Increased ductility and low strength were associated with the dissolution of beta particles into the alpha at the high temperatures.

The authors acknowledge the general assistance given by D. E. Harne throughout the investigation and the assistance given by J. Mackie with the metallography.

\section{References}

[1] Joint International Conference on Creep, New York and London, 1963 Papers, Inst. Mech. Engrs. (1963).

[2] Creep and Recovery, A seminar, Am. Soc. Metals (Cleveland, 1957).

[3] W. D. Jenkins and W. A. Willard, J. Res. NBS 70C (Engr. and Instr.) No. 1, 5 (Jan-Mar. 1966).

[4] J. deLacombe, Mémoires, Rev. Mét. 36

[5] J. J. Kanter, Trans. Am. Inst. Mining, Met. Engr. 13 1, 385 (1958)

[6] F. C. Monkman and N. J. Grant, Proc. Am. Soc. Testing Mater. 56, 593 (1956). 


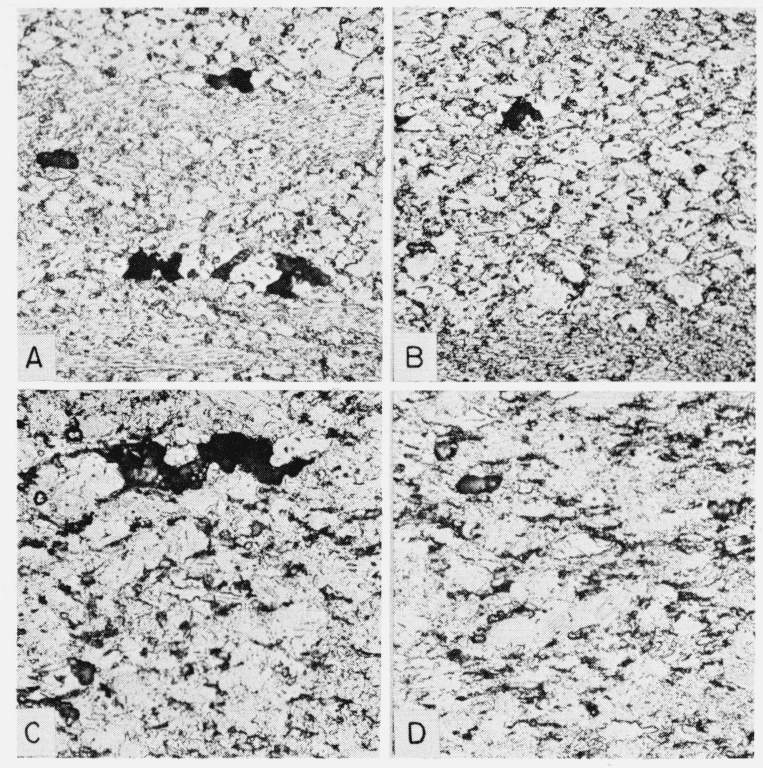

FIGURE 12. Effect of test time on microstructures of specimens tested to fracture at $1200^{\circ} \mathrm{F}$.

Longitudinal sections near axis. $\times 500$. Etched in a solution containing $4 \mathrm{ml} \mathrm{HF}, 6 \mathrm{ml}$ $\mathrm{HNO}_{3}$, and $100 \mathrm{ml} \mathrm{H}_{2} \mathrm{O}$.

\begin{tabular}{lc|r|l}
\hline \hline & Test time & Elongation & \multicolumn{1}{|c}{ Remarks } \\
\hline & \multicolumn{1}{c|}{$h r$} & $\%$ & \\
A & 13.8 & 90 & Near fracture \\
B & 13.8 & 90 & Same specimen as A; 0.2 in from fracture \\
C & 1450 & 184 & Near fracture \\
D & 1450 & 184 & Same specimen as C; 0.2 in from fracture \\
\hline
\end{tabular}

[7] F. R. Larson and J. Miller, Trans. Am. Soc. Mech. Engrs. 74, 765 (1952).

[8] W. D. Jenkins and W. A. Willard, J. Res. NBS 70C (Engr. and Instr.) No. 3, 195 (July-Sept. 1966).

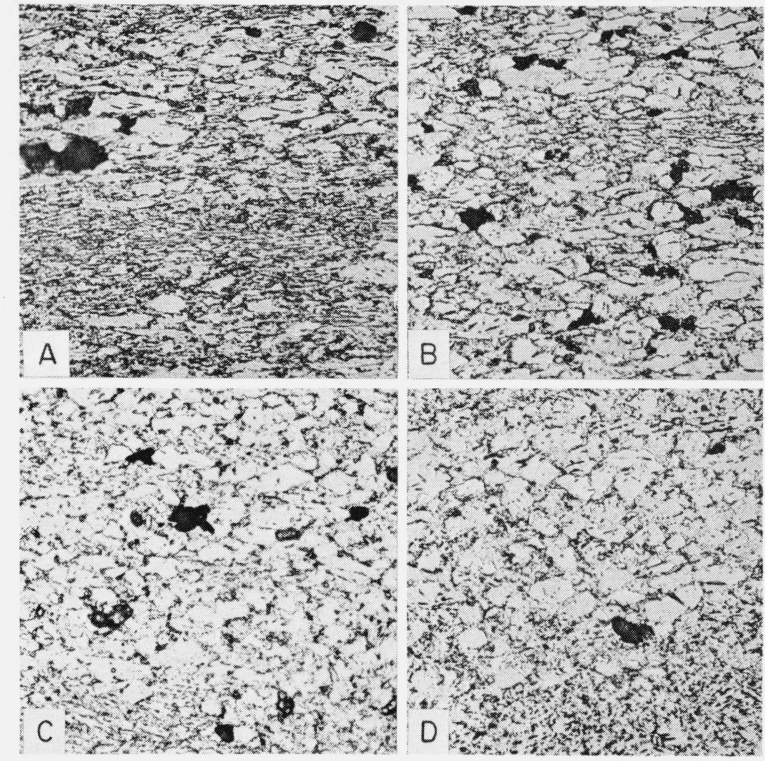

FIGURE 13. Effect of prior strain history on microstructures of specimens fractured in creep at $1000^{\circ} \mathrm{F}$ with stress of $30,000 \mathrm{psi}$.

Longitudinal sections near fracture. $\times 500$. Etched in a solution containing $4 \mathrm{ml} \mathrm{HF}, 6 \mathrm{ml}$ $\mathrm{HNO}_{3}$, and $100 \mathrm{ml} \mathrm{H}_{2} \mathrm{O}$.

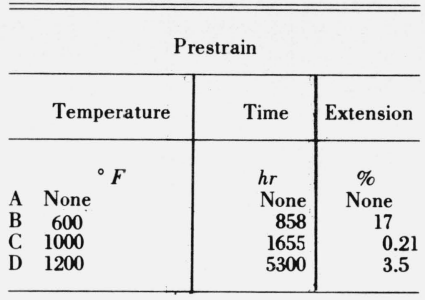

[9] W. D. Jenkins and T. G. Digges, J. Res. NBS 48, 313 (Apr. 1952) RP2317.

[10] W. D. Jenkins and W. A. Willard, J. Res. NBS 66C (Engr. and Instr.) No. 1, 59 (Jan.-Mar. 1962).

(Paper 72C2-275) 


\title{
Publications of the National Bureau of Standards*
}

\author{
Selected Abstracts
}

\begin{abstract}
Comparison of incompressible flow and isothermal compressible flow formulae, J. Hord, Tech. Note 356 (Aug. 17, 1967), 25 cents.

Mass flow formulae for incompressible and "modified-incompress. ible" flow are compared with the isothermal compressible flow relation under the following conditions: The gas flow is steady, isothermal, and fully developed in a horizontal pipe of constant cross section with a prescribed static pressure drop $\left(P_{1}-P_{2}\right)$. The comparative data are limited to static pressure ratios $\left(P_{2} / P_{1}\right)>\frac{1}{2}$, and subsonic isothermal flow. Laminar and turbulent flows are treated. Under the limitations of the comparison, modified-incompressible flow and isothermal gas flow relations are identical when
\end{abstract}

$$
f L / 2 D \gg \ln \left(P_{1} / P_{2}\right) .
$$

Graphical plots indicate the degree of approximation or error involved in using incompressible relations to solve compressible flow problems. Pressure losses due to end effects are briefly discussed.

Key Words: Compressible flow, flow comparison, fluid flow, incompressible flow, mass flow, pressure drop.

Correlations for predicting leakage through closed valves, J. Hord, Tech. Note 355 (Aug. 1, 1967), 20 cents.

Safety, convenience, and economy often demand the inference of leakage of a given fluid from known leakage of another test fluid across valve seats, welded and threaded fittings, seals, etc. The temperatures of the fluids also may be different. An example is the prediction of gaseous hydrogen leakage at $20{ }^{\circ} \mathrm{K}$ from test data obtained with nitrogen gas at $77^{\circ} \mathrm{K}$. Various flow formulae (molecular, transition, and continuum) are examined, and two simple methods of correlating leakage for single-phase fluids are deduced. The correlations obtained (excluding transition flow through long channels) indicate the leakage is inversely proportional to the square root of the density, or inversely proportional to the absolute viscosity, of the fluid. Thus, for gases, the leakage is directly proportional to the sonic velocity of the gas. The proper relationship must be established by experiment for each valve, fitting, etc.

Key Words: Leakage through valves, leak rates, leak detection, predicting leak rates, valve seat leakage, leak flow rates, seal leakage.

Designs for surveillance of the volt maintained by a small group of saturated standard cells, W. G. Eicke and J. M. Cameron, Tech. Note 430 (Oct. 9, 1967), 20 cents.

This technical note describes a procedure for maintaining surveillance over a small group of saturated standard cells. The measurement process is briefly discussed and the principle of left-right balance as a means of eliminating certain systematic errors is developed. Specific designs and their analysis for intercomparing $3,4,5$ and 6 cells in a single temperature controlled environment are given. Procedures for setting up control charts on the appropriate parameters are given, and a technique is described for detecting certain types of systematic errors.

Key Words: Control charts, experiment design, saturated standard cells, standard cells calibration, statistics, voltage standard.
Realistic uncertainties and the mass measurement process. An illustrated review, P. E. Pontius and J. M. Cameron, Mono. 103 (Aug. 15, 1967), 20 cents.

This paper gives a review of the concepts and operations involved in measuring the mass of an object. The importance of viewing measurement as a production process is emphasized and methods of evaluating process parameters are presented. The use of one of the laboratory's standards as an additional unknown in routine calibration provides an accuracy check and, as time goes on, the basis for precision and accuracy statements.

Key Words: Measurement, measurement process, uncertainty, mass measurement, precision, accuracy, statistical control.

Standard Reference Materials: Catalog and price list of standard materials issued by the National Bureau of Standards, Misc. Publ. 260, 1967 Edition (Sept. 15, 1967), 45 cents. (Supersedes NBS Misc. Publ. 260, 1965 Edition.)

This catalog describes the various Standard Reference Materials issued by the National Bureau of Standards. These materials are used to calibrate measurement systems and provide scientific information that can be referred to a common base. A schedule of prices and quantities is included for each material, as well as directions for ordering. Listed are the types and compositions of those chemical standards that are presently available. Announcements of new standard reference materials are made in the Federal Register, in scientific and trade journals, and in the Technical News Bulletin of the National Bureau of Standards. Changes affecting the current status of the various standards will be indicated by an insert sheet available quarterly from the Bureau.

Key Words: Analysis, catalog, certificate, characterization, composition, price list, property of material, purity of material, standard reference materials, standards.

Standard $x$-ray diffraction powder patterns, H. E. Swanson, H. F. McMurdie, M. C. Morris, and E. H. Evans, Mono. 25, Sect. 5 , (Aug. 31, 1967), 55 cents.

Standard $x$-ray diffraction powder patterns are presented for 80 substances. Thirty-nine of these patterns represent experimental data and 41 are calculated. The experimental $x$-ray powder diffraction patterns are made with a Geiger counter x-ray diffractometer, using samples of high purity. All $d$-values were assigned Miller indices determined by comparison with theoretical interplanar spacings and from consideration of space group extinctions. The densities and lattice constants were calculated, and the refractive indices were measured whenever possible. The calculated $x$-ray powder diffraction patterns were obtained from published crystal structure data. The reported peak height intensities for calculated patterns were converted from integrated intensities.

Reference intensity values based upon the strongest line of corundum (113) in a 50 percent weight mixture are given for 73 materials.

Key Words: standard, x-ray diffraction, powder-patterns, crystal, structure, measurements, lattice, constants, reference-intensities.

$X$-ray wavelength conversion tables and graphs for qualitative electron probe microanalysis, K. F. J. Heinrich and M. A. M. Giles, Tech. Note 406, (Sept. 25, 1967), 70 cents. 
Tables and graphs have been constructed for electron probe $\mathrm{x}$-ray spectrometers equipped with crystal changers and calibrated for $\mathrm{LiF}$ crystals in angstroms. These tables indicate the equivalent reading for the lines which can be normally expected to appear in wavelength scans using the following crystals: LiF, EDDT, ADP, KAP, and Pb stearate (LSD). The readings were extracted from the tables of E. W. White, et al. The tables are arranged by the atomic numbers of the emitting elements; the graphs show the readings for observable lines as a function of atomic number for each of the aforementioned crystals. A suggested method for using the tables and graphs is included.

Key Words: X-ray spectrometers, wavelengths, electron probe microanalyzer, $\mathrm{x}$-ray emission.

Field burnout tests of apartment dwelling units, D. Gross, Bldg. Sci. Series 10 (Sept. 29, 1967), 25 cents.

Results are reported of three burnout tests in an experimental test building, using a wood crib fuel load of $6 \mathrm{lb} / \mathrm{ft}^{2}$, representing combustible contents, and a structural design load of $40 \mathrm{lb} / \mathrm{ft}^{2}$ applied to the floor or roof above the test room. Measurements were made of temperature, radiation, smoke, gas composition, and structural deflection. A discussion of the fire performance of materials and methods of construction, and conclusions with regard to specific fire-protective objects are presented.

Key Words: Burnout test, fire performance, apartment dwelling, smoke, flame penetration, structural load, potential heat, fire load.

"Life cycling" test on several strain gage pressure transducers, P. S. Lederer, Tech. Note 434 (Oct. 1967), 20 cents.

This publication reports the effects of many thousands of pressure cycles on the performance characteristics of several types of strain gage pressure transducers. The results obtained indicate permanent changes in zero pressure output and sensitivity. Most of these changes tend to occur during the first few thousands of cycles. The equipment and procedures used to obtain the data are described. Key Words: Life cycling, pressure cycling, life testing, pressure transducer, strain gage.

Organic Chemistry; Air pollution studies characterization of chemical structures; synthesis of research materials; novel research materials; isotopic methods for analysis of carbohydrates; occurrence, preparation, and properties of naturally occurring monosaccharides (including 6-deoxy sugars); standard reference materials (organic) July 1966 through June 1967, Ed. R. Schaffer, Tech. Note 427 (Oct. 1967), 45 cents.

This report describes work in progress in the Organic Chemistry Section of the Analytical Chemistry Division of the NBS Institute for Materials Research. The following research areas are discussed: Air Pollution Studies. Information has been obtained on the detection of impurities in, and the purification of, commercial samples of certain polycyclic, aromatic hydrocarbons that are known to occur in polluted air. The oxidation of these hydrocarbons under conditions resembling those encountered in polluted areas has been studied, and some of the products have been identified.

Characterization of Chemical Structures. The infrared absorption spectra of a group of 2-oxo-1,3-bis(phenylhydrazono) derivatives have been studied, and compared with the spectra of four tris(phenylhydrazones) and six related mono- and bis-(phenylhydrazono) derivatives, in order to identify the important features of the bands arising from $\mathrm{N}=\mathrm{N}, \mathrm{N}-\mathrm{H}$ (bending), and $\mathrm{Ph}-\mathrm{N}$ groups. In addition, the phenylhydrazono-phenylazo tautomerism of 2-oxo-1,3-bis (phenylhydrazono) compounds has been elucidated. A novel aromatization of inositols in methyl sulfoxide-acetic anhydride has been discovered.

Synthesis of Research Materials: A Disaccharide of D-Lyxofuranose. A compound formed in the high-vacuum distillation of $2,3-o$-isopropylidene- $\alpha$-D-lyxofuranose has been obtained crystalline by acetylation, crystallization of the diacetate, and saponification of the latter. From the results of oxidation, reduction, hydrolysis, and nuclear magnetic resonance studies, the compound is believed to be the di-o-isopropylidene acetal of 5-o- $\alpha$-D-lyxofuranosyl- $\alpha$-D-lyxofuranose. This is the first known example of a thermal condensation providing a reducing disaccharide in which both sugar moieties are furanoid.
Novel Research Materials. The reaction of sulfonic esters of alditols with methoxide has been examined, and a new dianhydrohexitol has been isolated. The literature on the infrared spectroscopy of carbohydrates has been critically evaluated and systematized.

Isotopic Methods for Analysis of Carbohydrates. The various methods of isotope-dilution analysis, the isotope effects that may accompany studies with labeled molecules, and the methods for determining isotopic distribution have been assessed and assembled.

Occurrence, Preparation, and Properties of Naturally Occurring Monosaccharides, Including 6-Deoxy Sugars. A survey has been made of all of the monosaccharides and 6-deoxy sugars that are known to occur naturally, and their preparation has been reviewed. In addition, their chemical and physical properties have been collated.

Standard Reference Materials. The preparation of highly pure samples of quebrachitol, levo-inositol, 1,2-o-isopropylidene- $\beta$-L-idofuranose, and 2,3-o-isopropylidene- $\beta$-D-threo-pentulofuranose has been achieved, and the compounds have been characterized by melting point, specific optical rotation, and infrared absorption spectrum. These compounds are now available to the public as standard reference materials.

In order to describe experimental procedures adequately, it has occasionally been necessary to identify commercial materials and equipment in this report. In no case does such identification imply recommendation or endorsement by the National Bureau of Standards, nor does it imply that the material or equipment identified is necessarily the best available for the purpose.

Key Words: Air pollution studies, oxidation of polycyclic aromatic hydrocarbons, characterization of chemical structures, phenylhydrazono-phenylazo tautomerism, disaccharide of D-lyxofuranose, infrared absorption methods for analysis of carbohydrates, naturally occurring monosaccharides and 6-deoxy sugars, standard reference materials, quebrachitol, levo-inositol, 1,2-o-isopropylidene- $\beta$-Lidofuranose, 2,3-o-isopropylidene- $\beta$-D-threo-pentulofuranose.

Radiometric methods for measuring laser output, D. A. McSparron, C. A. Douglas, and H. L. Badger, Tech. Note 418 (Nov. 1967), 15 cents.

The output of pulsed lasers may be measured with reasonable accuracy by modifications of established radiometric methods. The receiver, thermopile or phototube, is used ballistically. It is calibrated by an incandescent-lamp standard of spectral irradiance. The laser beam is attenuated to make its irradiation on the receiver comparable to that from the calibrating source. Attenuation is accomplished by intercepting the entire laser beam on a diffusely reflecting surface. The attenuation factor is determined from direct measurement of the reflectance of this diffusing surface and the geometric constants of the system. The accuracy of the measurement of laser output is dependent upon the accuracy of calibration of the standard of spectral irradiance and the accuracy with which the spectral sensitivity of the receiver, the spectral transmittance of the band-pass filters, and the reflectance of the diffuser can be determined. Measurements made with different photoelectric receivers agree to about $1.5 \%$ using a $1 / 4$-joule pulsed ruby laser as a source. Total uncertainty is estimated to be about $5 \%$. Measurements made using these radiometric methods have been compared with calorimetric measurements and a discrepancy of $9 \%$ was observed.

Key Words: Laser. radiometry, laser energy measurement, radiometric calibration, photoelectric photometry, optical attenuator

Second breakdown in semiconductor devices-A bibliography, H. A. Schaff, Tech. Note 431 (Oct. 1967), 30 cents.

Almost 200 references with appropriate key words are listed which provide, it is believed, a comprehensive coverage of the literature of second breakdown in transistors and other semiconductor devices from 1958 through much of 1967. A representative list of earlier papers dealing with what appears to be second breakdown in pointcontact and $\mathrm{p}-\mathrm{n}$ junction diodes is also included. The indexes consist of an author index and an index to subject matter with reference tabulations and with key word assignments.

Key Words: Bibliography, semiconductor devices, transistors, diodes, second breakdown, thermal breakdown, device reliability, failure modes, failure mechanisms. 
X-ray wavelengths, J. A. Bearden, NSRDS-NBS 14 (Sept. 25, 1967), 40 cents.

Inconsistencies in accepted values (in $x$ units) of $\mathrm{x}$-ray reference lines have recently been demonstrated, although all are supposedly based on "good" calcite crystals. Factors supporting the selection of the W $K \alpha_{1}$. line as the X-Ray Wavelength Standard are critically discussed. A review is given of the experimental measurements which are used to establish the wavelength of this line on an absolute angstrom basis. Its value is $\lambda \mathrm{W} K \alpha_{1}=(0.2090100 \pm 5 \mathrm{ppm}) \AA$. This may be used to define a new unit, denoted by $\AA^{*}$, such that the W $K \alpha_{1}$ wavelength is exactly $0.2090100 \AA^{*}$; hence $1 \AA^{*}=1 \AA \pm 5 \mathrm{ppm}$. The wavelengths of the $\mathrm{Ag} K \alpha_{1}$, Mo $K \alpha_{1}$, Cu $K \alpha_{1}$, and the $\mathrm{Cr} K \alpha_{2}$ have been established as secondary standards with probable error of approximately one part per million. Sixty-one additional x-ray lines have been used as reference values in a comprehensive review and reevaluation of more than 2700 emission and absorption wavelengths. The recommended wavelength values are listed in $\AA^{*}$ units together with probable errors; corresponding energies are given in $\mathrm{keV}$. A second table lists the wavelengths in numerical order, and likewise includes their energies in $\mathrm{keV}$.

Key Words: Absorption, atomic, data compilation, emission, energy level, x-ray wavelength.

Reevaluation of x-ray atomic energy levels, J. A. Bearden and A. F. Burr, NSRDS-NBS 14 (Sept. 25, 1967), 40 cents.

All of the x-ray emission wavelengths have recently been reevaluated and placed on a consistent $\AA^{*}$ scale. For most elements these data give a highly overdetermined set of equations for energy level differences, which have been solved by least-squares adjustment for each case. This procedure makes "best" use of all $x$-ray wavelength data, and also permits calculation of the probable error for each energy difference. Photoelectron measurements of absolute energy levels are more precise than x-ray absorption edge data. These have been used to establish the absolute scale for eighty-one elements and, in many cases, to provide additional energy level difference data. The x-ray absorption wavelengths were used for eight elements and ionization measurements for two; the remaining five were interpolated by a Moseley diagram involving the output values of energy levels from adjacent elements. Probable errors are listed on an absolute energy basis. In the original source of the present data, a table of energy levels in Rydberg units is given. Difference tables in volts, Rydbergs, and milli- $\AA^{*}$ wavelength units, with the respective probable errors, are also included there.

Key Words: Absorption, atomic, data compilation, emission, energy levels, x-ray wavelength.

A method of producing sturdy specimens of pressed powders for use in x-ray spectrochemical analysis, B. L. Bean, Appl. Spectry. 20, No. 3, 191-193 (May-June 1966).

Sturdy specimens of compacted or pressed powders may be produced for x-ray spectrochemical analysis as follows: A sleeve with sides about $0.16 \mathrm{~cm}(1 / 16 \mathrm{inch})$ thick and diameter $0.02 \mathrm{~cm}$ less than the inside diameter of the mold is placed in the mold. The powder is spread on the lower plunger of the mold. The sleeve is then removed and boric acid poured in the formed peripheral trench and on top of the powder. The specimen is then pressed. A specimen with strong edges and backing is prepared that may be reused many times because the boric acid edges support the pressure of the sample holder instead of the pressed sample powder.

Key Words: Boric acid edges, pressed powders, sturdy specimens, x-ray spectrochemical analysis.

Aromatic fluorocarbon polymers, W. J. Pummer and J. M. Antonucci (Proc. 152d American Chemical Society Meeting, New York, N.Y., Sept. 13, 1966), Polymer Preprint 7, No. 2, 1071-1076 (Sept. 1966).

Recent synthetic work has led to the preparation of a variety of fluoroaryl polymers. Most of the polymers synthesized are similar in structure to the hydrocarbon analogs except for the fluorine atoms. On this basis, the fluorinated polymers, presented in this paper, will be classified and discussed according to structural features. The first class of polymers contains the polyperfluorophenylenes which will include both the para and meta linked polymers. In the second class, the polymers contain an atom or group of atoms between the fluorinated rings, such as oxygen, sulfur and oxydifluoromethylene groups.
Some polymers in this category are the polyperfluorophenylene ethers and sulfides. The final group of polymers contains a pendant pentafluorophenyl ring attached to the main polymer chain such as the various fluorinated styrenes and vinyl ethers.

In all cases, the method of polymerization, physical properties and thermal stability of the polymers will be discussed and whenever possible, comparisons will be made between the fluorinated and hydrocarbon polymers.

Key Words: Fluorinated styrenes; fluoroaryl polymers; para, meta linked polymers; pendant pentafluorophenyl ring; polyperfluorophenylene ethers, sulfides; polyperfluorophenylenes; vinyl ethers.

Calculation of currents of local galvanic cells, J. A. Simmons, S. R. Coriell, and F. Ogburn, J. Electrochem. Soc. 114, No. 8 , 782-787 (Aug. 1967)

The current flow for a local electrolyte cell with rectangular anode and cathode is calculated as a function of polarization parameter, electrolyte thickness and conductivity, anode and cathode size, and zero current potential difference. The total current is obtained from the numerical computation (with error analysis) of a series solution of Laplace's equation assuming a linear polarization relation at the electrode-electrolyte interface. For high values of the polarization parameter and sufficiently thick electrolytes an asymptotic formula obtains for the current approximately proportional to the anodic fraction - as was found by Waber et al. However, in general the cell geometry greatly influences the amount of current flow, especially for anode shapes near to linear rather than square. This effect can be greater than an order of magnitude. The calculated results are compared with experimental data obtained by Ogburn and Schlissel and are shown to be in good agreement. Corrosion currents in randomly pitted surfaces may be estimated from the above results.

Key Words: Corrosion currents, galvanic cells, galvanic currents, Laplace's equation, pitting corrosion.

Crystallization of natural rubber, N. Bekkedahl, Rubber Chem. Technol. 40, No. 3, xxv-xlvii (June 1967).

This review article presents a resume of the research work that has been done at the National Bureau of Standards during the past 35 years in the field of crystallization of polymeric materials, with special emphasis on natural rubber. It contains only information on results of research work that has already been published.

Key Words: Polymers, rubber, crystallization, melting, dilatometry, stark rubber, chain folding, heat engine, contractility.

Determination of bound styrene in insoluble emulsion polymerised styrene-butadiene copolymers, M. A. Post, J. Appl. Chem. 17, 203-208 (July 1967).

Bound styrene is determined in insoluble emulsion polymerized styrene-butadiene copolymers by measurement of the $10.3 \mu \mathrm{m} /$ $13.2 \mu \mathrm{m}$ absorbance ratio using the baseline method. This ratio is obtained from the infrared spectrogram of the copolymer and the percent styrene is determined from a standard curve. The standard curve is constructed from absorbance ratios of $10.3 \mu \mathrm{m} / 13.2 \mu \mathrm{m}$ derived from the infrared spectrograms of cast films of styrenebutadiene latexes over a range of percentage compositions. Bound styrene is determined in these latexes by nitration of the isolated and extracted copolymers. Styrene content based on nitration is determined from standard curves relating styrene concentration to spectrophotometric absorbance measurements at wavelengths of $285.0 \mathrm{~nm}, 273.8 \mathrm{~nm}$ and $265.0 \mathrm{~nm}$. The source of the styrene for these curves is NBS standard rubber \# 1500 .

Key Words: Absorbance ratio method, bound styrene, infrared, insoluble styrene-butadiene copolymers, masonry paints.

Electrical conductivity of high purity copper, J. J. Gniewek, J. C. Moulder, and R. H. Kropschot, Proc. LT-10 Conf., Moscow, USSR, Aug. 31-Sept. 9, 1966.

The low temperature electrical conductivity of copper single crystals $\left(R_{273} / R_{4}>30,000\right)$ and polycrystalline wire $\left(R_{273} / R_{4}>10,000\right)$ has been measured between $4{ }^{\circ} \mathrm{K}$ and $77^{\circ} \mathrm{K}$.

Between 14 and $30{ }^{\circ} \mathrm{K}$ the resistance is proportional to $T^{n}$ where $n=4.8+0.1$. Size effects are observed using both eddy current and direct current techniques in samples as large as $2 \mathrm{~mm}$ in diam. 
eter. Assuming diffuse reflection of the electron from the surface direct current size effect measurements give a

$$
\rho_{b} l_{b}=0.53 \times 10^{-11} \Omega \mathrm{cm}^{2}
$$

which is less than the free electron value of $0.66 \times 10^{-11} \Omega \mathrm{cm}^{2}$.

Key Words: Copper, electrical conductivity, low temperature, size effect.

Epitaxial growth of iron on tungsten field emission points, A. J. Melmed, Surface Sci. 7, No. 3, 478-481 (July 1967).

Iron crystals can be grown from the vapor phase on tungsten field emission points. The crystals tend to nucleate at edges of $\mathrm{W}(011)$ planes and grow in the same orientation as the substrate, sometimes with an apparent small parallel displacement. Inter-diffusion of $\mathrm{W}$ into the growing $\mathrm{Fe}$ crystals can occur and evidence for this is presented.

Key Words: Epitaxy, field emission microscopy, crystal growth, vapor deposition, $\mathrm{Fe}-\mathrm{W}$ alloying.

Growth of large sodium chloride crystals from solution for color center studies, P. M. Gruzensky, J. Chem. Phys. 43, No. 11, 3807 (Dec. 1, 1965).

Sodium chloride single crystals with edge dimensions as large as $2.5 \mathrm{~cm}$ were grown from aqueous solutions. Solutions were purified by chemical precipitation of trace contaminants and filtration through membrane filters. Crystal defects were apparent in in the initial stages of growth, but the outer portions of crystals were free of dislocations. F-band coloration by $x$ rays at room temperature was not linear and the "first stage" was either absent or nearly so. Transition from extrinsic to intrinsic dc conductivity occurred at $350 \mathrm{C}$ with the extrinsic conductivity two orders of magnitude lower than for "pure" melt-grown crystals.

Key Words: Alkali halides, aqueous, color centers, chloride, conductivity, crystal growth, and sodium.

Helium field-ion microscopy of hexagonal close-packed metals, A. J. Melmed (Proc. Symp. The Structure of Surfaces, Durham, N. C., Nov. 1966), Surface Sci. 8, No. 12, 191-205 (JulyAug. 1967).

The atomic structure of curved hexagonal close-packed metal surfaces is complicated compared to curved surfaces of body-centered cubic metals. He field-ion microscopy of $\mathrm{Ru}$ and $\mathrm{Re}$ field-evaporated surfaces discloses apparent differences in the surface structures developed under similar experimental conditions. The effect of temperature and field strength on the structure developed by fieldevaporation is analyzed, and the structures of the (100) and (001) plane regions in particular are discussed in relation to their respective field-ion images.

Key Words: Field-ion microscopy, field evaporation, surface structure and hexagonal close-packed metals.

High pressure adsorption isotherms of neon, hydrogen, and helium at $76{ }^{\circ} \mathrm{K}$, A. J. Kidnay and M. J. Hiza (Proc. 1966 Conf., Boulder, Colo., June 13-15, 1966), Book, Advances in Cryogenic Engineering 12, 730-740 (Plenum Press Inc., New York, N.Y., 1967). A desorption technique was used to measure the physical adsorption isotherms of hydrogen and helium on a synthetic zeolite and hydrogen, helium, and neon on an activated cocoanut shell charcoal at $76^{\circ} \mathrm{K}$ in the pressure range of 1 to 95 atmospheres.

The Polanyi adsorption potential theory, as modified by Dubinin, was used in an attempt to obtain a general correlation of these isotherms. The results, while not completely general, should allow the prediction of the high pressure isotherms of neon, hydrogen, and helium at any temperature with an accuracy sufficient for most engineering calculations.

Key Words: Adsorption potential, charcoal, helium, high-pressure physical adsorption, hydrogen, low temperature, neon, zeolite.

History of the National Standard of electromotive force, W. J. Hamer (Proc. 22nd ISA Conf. and Exhibit, Chicago, Ill.,
Sept. 11-14, 1967), ISA Preprint No. M2-1-MESTIND-67, pp. $1-10,(1967)$.

The history of the National Standard of electromotive force is traced from the meeting of the International Electrical Congress in Chicago in 1893 to the present time. Included are discussions of the transfer of the "volt standard" from its old location in Washington, D.C., to its new location near Gaithersburg, Md., of the stability of standard cells, of the application of Gibbs' Phase Rule to standard cells, and the relation between the legal and absolute volts.

Key Words: Volt standards, legal volt, absolute volt, Gibbs' phase rule, history of volt.

Indentation hardness of the fingernail, S. B. Newman and R. W. Young, J. Invest. Dermatol. 49, No. 1, 103-105 (Mar. 17, 1967). Indentation hardness using the Knoop indenter has been used as a quantitative criterion in physiological studies of the human nail plate. Data were collected and are presented to show that values reported in the literature are in serious error. A number of parameters affecting Knoop numbers are examined in an effort to determine the source of error.

Key Words: Fingernail, Knoop indenter, hardness.

Polymerization of fluoroolefins and related monomers, L. A. Wall (Proc. 152nd American Chemical Society Meeting, New York, N.Y., Sept. 13, 1966), Polymer Preprint 7, No. 2, 1112-1115 (Sept. 1966).

Although some fluorine-containing monomers polymerize readily, there are many which have not as yet been polymerized either by free radical or ionic catalysts. In order to investigate the reasons for the somewhat general tendency of these monomers to resist polymerization, we have initiated a systematic study using high pressures and $\gamma$-rays to induce polymer formation.

The technique has been successful for many fluoro monomers, fluoropropylenes, fluorodienes, perfluorostyrene and some fluorovinyl phenyl ethers. In a general way, the results suggest in many cases that slow propagation steps, easy transfer processes with monomer or impurities, and in some cases a tendency to thermally dimerize, interfere with the formation of high polymer.

Key Words: Fluorine-containing monomers, fluorodienes, fluoro monomers, fluoropropylenes, fluorovinyl, free radical, gamma-rays, high pressures, ionic catalysts, perfluorostyrene, phenyl ethers.

A computer simulation model of railroad freight transportation systems, W. P. Allman, Intern. Railway Cong. Assoc. Mo. Bull. Cybernetics and Electronics 4, No. 2, 45-57 (Feb. 1967). A railroad may be viewed as a network of nodes (yards) and links (railroad lines), with time-dependent demands for the movement of freight cars imposed upon it. Incident to car movement are the following key operating policy questions of railroad freight operations:

a) When and where should regularly-scheduled trains run?

b) For each yard, what should the car classification (sorting) policy be?

c) Over each link of a train's route, what cars should be assigned to the train for hauling?

These interdependent questions must be answered simultaneously, and in accordance with overall operating objectives of the railroad enterprise. Policies must be revised periodically when significant changes in demand traffic patterns occur.

The paper describes a simulation model which permits experimentation with various alternative railroads freight operating policies at a total-network level. The model has been constructed with the SIMSCRIPT simulation programming language. Model inputs include time-dependent freight car origin-destination demand data, train routes and schedules, yard sorting and operation policies, and assignments of cars to trains for hauling. Freight cars are sorted at yards, and picked up and dropped off by trains which haul them thru the network. Model outputs include several railroad operation performance measures such as origin-destination transit times, activity volumes, train lengths, delays incurred by cars at yard operations, and operating costs.

Key Words: Railroad freight transportation systems, computer simulation model, transportation systems, network-simulation. 
A precision noise-power comparator, M. G. Arthur, C. M. Allred, and M. K. Cannon, IEEE Trans. Instr. Meas. IM-13, No. 4, 301-305 (Dec. 1964).

This paper describes a prototype noise power comparator based upon a theory given by Allred. Operating at $3 \mathrm{MHz}$, it is a nulltype instrument, the principal components of which are a reference CW voltage generator, a hybrid four-port, a dual-channel amplifier and band-pass filter, and an analog multiplier. Unlike other radiometers, no rapid switching of the noise power or reference voltage is performed.

The instrument can compare noise powers having effective noise temperatures in the range from below liquid nitrogen temperature to greater than $30,000{ }^{\circ} \mathrm{K}$. Two noise generators having known spectral densities are used to calibrate the comparator. The accuracy of comparison is $1 \%$ at $77{ }^{\circ} \mathrm{K}$ and increases to $0.2 \%$ at $29,000{ }^{\circ} \mathrm{K}$.

Key Words: Analog multiplier, attenuator, band-pass filter, hybrid four-port, noise-power comparator, noise powers, noise temperatures, radiometer.

Microprinting fills the bill, B. M. Fry, Business Graphics, pp. 21-25 (Jan. 1967).

The Clearinghouse for Federal Scientific and Technical Information, part of NBS, is a focal point for the collection, announcement and sale of copies of unclassified U.S. Government R\&D reports released for public sale by the sponsoring Federal agencies. Approximately 50,000 new reports and Government-sponsored translations of foreign technical material are received each year. The article describes Clearinghouse reproduction services as part of the system to meet the demand for over $2,000,000$ copies of documents in microfiche and paper copy each year. The Clearinghouse reproduction plant makes use of the latest technology in microphotography, electrostatic copying and offset printing. The article highlights the role of the reproduction plant as a laboratory in testing new equipment and ideas to improve service to customers.

Key Words: Clearinghouse for Federal Scientific and Technical Information, microphoto, microprinting, printing, systems.

Microwave standards and measurements in the USA, R. W. Beatty (Proc. XV General Assembly of URSI, Munich, Germany, Sept. 5-15, 1966), Book, Progress in Radio Science 1963-1966, Part 1, pp. 194-260 (International Scientific Radio Union, Munich, Germany, 1966).

A report is given on progress within the U.S.A. in the development of radio standards and measurement methods at frequencies from 1 to $300 \mathrm{GHz}\left(\mathrm{GHz}=10^{9}\right.$ cycles per second). The period covered is the three years 1963-1966. The following topics are included within the scope of this report: power; noise; reflection coefficient and impedance; phase shift; attenuation and loss; and field strength and antenna gain.

Key Words: Antenna gain, attenuation, field strength, impedance, measurement, microwave, noise, phase shift, power, progress, reflection coefficient, review, standards, survey.

Proposed recommended practice for description and selection of conditions for photographing specimens, C. S. McCamy, Photo. Sci. Eng. 10, No. 4, 185-191 (July-Aug. 1966). A "Proposed Recommended Practice for Description and Selection of Conditions for Photographing Specimens" has been prepared for the American Society for Testing and Materials so that the photographic method of recording appearance can be made more reproducible from one laboratory to another, for various specimens, and for a given specimen at different times. The proposal defines terms and symbols and provides a systematic method of describing the arrangement of lights, camera, and subject; the characteristics of the illumination; the nature of the photographic process, and the viewing system. Conditions for photographing certain common forms of specimens are recommended. Conventions for exhibiting and publishing photographs of specimens include an orientation mark and a coordinate system for pictures.

Key Words: Specimen photography, camera description, lighting description, appearance.

Protection circuit insulated for high voltage, E. Niesen, Rev. Sci.Instr. 38, No. 5, 689 (May 1967).
A circuit using standard components for floating an optical meter relay at high voltage is presented. By plugging in available optical meter relays, sensitivities in microamperes to amperes, millivolts to kilovolts can be controlled for a high or low limit.

Key Words: Optical meter relay, protection circuit.

Size and power requirements of $4.2{ }^{\circ} \mathrm{K}$ refrigerators, T. R. Strobridge and D. E. Chelton (Proc. 1966 Conf., Cryogenic Engineering, Boulder, Colo., June 13-15, 1966). Book, Advances in Cryogenic Engineering 12, 576-584 (Plenum Press Inc., New York, N.Y., 1967). A survey to determine the physical characteristics of $4.2^{\circ} \mathrm{K}$ cyclic refrigetators is presented. Although the data acquired through the survey show considerable scatter, the expected trends can be detected and attempts have been made to establish guides by which the weight, volume, and power requirements for various capacity refrigerators may be estimated. No attempt is made to assess the reliability, the interval of maintenance free operation, or the capital costs.

Key Words: $4.2{ }^{\circ} \mathrm{K}$ refrigerators, cyclic refrigerators, liquid helium, power requirements, size requirements.

Slush hydrogen characteristics, D. B. Mann, C. F. Sindt, P. R. Ludtke, and D. B. Chelton, Proc. Conf. Long-Term Cryo-Propellant Storage in Space, National Aeronautics and Space Administration, Huntsville, Ala., Oct. 12-13, 1966.

The utilization of slush hydrogen as an upgraded fuel is dependent upon knowledge of its physical and transport properties and characteristics. A NASA-sponsored program designed to acquire this information is in progress.

Experimental measurements of solid particle size distribution, aging effects and terminal velocities of the solid particles in the liquid melt have been completed. Transport characteristics have been predicted using these measured parameters. These predictions are currently being submitted to experimental verification.

Two 100 gallon dewars connected by 75 feet of vacuum-insulated transfer line comprise the experimental flow loop. Pressure sensing transducers and visual observation through glass ports allow acquisition of transport data over a broad range of flow rates.

Handling and investigative techniques such as dewar-to-dewar transfer, straining of the solids through wire mesh screen, and vertical temperature profiles of the settled mixture are presented in the context of a continuing experimental and analytical research program.

Key Words: Cryogenic, fluid transport, freezing, hydrogen-liquid solid, production.

The role of NBS in motor vehicle satefy research, $\mathrm{P}$. J. Brown, Proc. Regional Meeting Society Automotive Engineers, Gaithersburg, Md., April 18, 1967, SAE 670204, p. 3 (June 1967).

The relationship of the National Traffic Safety Agency and NBS and an outline of the research programs in tire systems, occupant restraint systems, and braking systems. The immediate goals and objectives as well as the long-range objectives will be stipulated.

Key Words: Tire system research, occupant restraint system research, braking system, research information exchange, role of NBS motor vehicle safety.

A modified Monte-Carlo quadrature. II, S. Haber, Math. Compt. 21, No. 99, 388-397 (July 1967).

A modification of Simple Monte-Carlo quadrature is proposed, which uses very simple forms of stratified sampling and of the "method of antithetic variates." The new procedure is fully automatic-requiring no preliminary analysis of the integrand-and converges somewhat faster than Simple Monte-Carlo. Results of experimental calculations are presented.

Key Words: Mathematics, analysis, numerical analysis, integration, numerical integration, quadrature, Monte-Carlo, multiple integration.

Current distribution and impedance of lossless conductor systems, R. L. Brooke and J. E. Cruz, IEEE Trans. Microwave Theory Tech. MTT-15, No. 6, 358-364 (June 1967). 
A general method for determining the characteristic impedance of lossless, uniform, go and return systems is developed. The current distribution within the system is determined by means of a matrix equation programed for computer solution. Knowing the current distribution, the inductance per unit length and characteristic impedance are obtained. The results obtained by applying this method to several rectangular coaxial systems are compared with the predictions of an approximate analytic expression. The reflection coefficient of a variable characteristic impedance coaxial line is measured on a "Time Domain Reflectometer" (TDR) and the results are compared with both the matrix method and the approximate analytic expression.

Key Words: Characteristic impedance, current distribution, general method, matrix solution, rectangular transmission line, time-domain reflectometer, variable impedance.

The spheroidal method in satellite astronomy, J. P. Vinti, Book, Space Mathematics 5, Part 1, 119-129 (American Mathematical Society, Providence, R.I., 1966).

To calculate the drag-free orbit of an artificial satellite of an oblate planet, the author has devised a very accurate approximation for it gravitational potential, leading to separability of the problem in oblate spheroidal coordinates. The present paper sketches the procedures for finding this potential and for calculating the corresponding orbit. It then discusses the remaining perturbing potential and a method for accounting for its effect on the orbit.

Key Words: Artificial satellite, drag-free orbit, gravitational potential, oblate planet, oblate spheroidal coordinates, satellite astronomy, spheroidal method.

A systems concept of electromagnetic measurements in the U.S.A., G. E. Schafer, Proc. IEEE 55, No. 6, 775-778 (June 1967) Abstract is not required, but the following summary describes contents of manuscript. A brief description of a systems concept of the National Measurement System proposed by Dr. R. D. Huntoon, Director, Institute for Basic Standards, is given first. Activities of the Radio Standards Laboratory as a functional element of this system are then described. Some benefits of looking at RSL as an element of this system are given.

Key Words: National measurement system, radio standards, electromagnetic measurement.

Liquid hydrogen engineering instrumentation, T. M. Flynn (Proc. Intern. Inst. Refrigeration, June 9-11, 1965), Book, Liquid Hydrogen, pp. 295-338 (Paris, France, 1965).

Prudent liquid hydrogen engineering requires the measurement of both extensive and intensive properties of the cryogenic liquid. Transducers are required for liquid level (quantity), both point and continuous systems, and mass rate systems. In addition, there must be transducers of pressure, temperature, density, and occasionally, quality. This paper discusses some of the devices and practices currently used for the measurement of pressure, temperature, flow rate, and liquid level in liquid hydrogen systems.

Key Words: Cryogenics, instrumentation, liquid hydrogen, transducers.

Progress in the distribution of standard time and frequency, 1963 through 1965, J. M. Richardson (Proc. XV General Assembly of URSI, Munich, Germany, Sept. 5-15, 1966 ), Book, Progress in Radio Science 1963-1966, Part 1, pp. 40-62 (International Scientific Radio Union, Munich, Germany, 1966).

Progress in accurate long distance distribution of standard time and frequency, as reported in the literature from 1963 through 1965, is summarized. Techniques are by VLF, LF, and HF radio propagation, by satellite relay, and by portable clocks. Effects on standard frequency transmissions of variations in VLF propagation with geophysical phenomena are quantitatively understood. VLF and LF transmissions have provided careful, long-term, statistical comparison of remotely located atomic frequency standards. Precision of at least 2 parts in $10^{11}$ for a 24 -hour observation period is possible at $5000 \mathrm{~km}$. The phase of some standard frequency transmitters is routinely steered by VLF from distances up to $5300 \mathrm{~km}$. Global distribution of standard time by VLF to microsecond resolution has been shown feasible. The null beat between two neighboring VLF carriers propagates stably enough to mark a particular VLF cycle, and the beat period can be long enough to enable ordinary time signals to mark a particular null beat. Intercontinental time synchronization by microwave pulses has been accomplished via Telstar and Relay II satellites. Accuracy is observed to be at several microseconds. Portable cesium clocks have served as global transfer standards with degradation of timing accuracy of only about a microsecond per trip. Results by all the above methods are consistent with each other and with stated accuracies of atomic standards involved.

Key Words: Time, frequency, time signals, standard frequency broadcasts, VLF propagation, portable clocks.

Progress in the United States on electromagnetic standards and measurements at $30 \mathrm{kHz}$ to $1 \mathrm{GHz}, 1963$ through 1965 , M. C. Selby, IEEE Trans. Instr. Meas. IM-16, No. 2, 172-178 (June 1967).

A digest of highlights is presented on the most significant U.S. contributions to the measurement of attenuation, impedance, voltage, current, field strength, thermal noise, and phase at $30 \mathrm{kHz}$ to $1 \mathrm{GHz}$. A total of approximately 30 contributions are digested in this section of the report. The following accomplishments are among them: a supersensitive detector for a complex-insertion-ratio measurement system having accuracies of about $0.0005 \mathrm{~dB} / 10 \mathrm{~dB}$ at $30 \mathrm{MHz}$; exact equations for mutual and self-inductance of various combinations of filaments, tapes, and bars; a modified Twin-T-Bridge for measuring resistances of 100 to $10,000 \mathrm{ohms}$ to $15 \mathrm{MHz}$; a set of $Q$-factor standards for frequencies to $45 \mathrm{MHz}$ based on accumulated data and experience over 5 years; a unique adjustable characteristic-impedance coaxial line measurement of $Q$ 's greater than 100,000 of cryogenic circuits at frequencies to $300 \mathrm{MHz}$; a novel Tee-junction to enable calibrations of voltmeters of any practicable input impedances with VSWR's ranging from 1 to 200 , to $1 \mathrm{GHz}$ and higher; a miniaturized dipole-antenna field strength meter, employing a semiconducting plastic transmission line, to measure complex near-zone fields of 0.1 to 1000 volts per meter, from $150 \mathrm{kHz}$ to 30 $\mathrm{MHz}$; a prototype $3-\mathrm{MHz}$ model of precision thermal noise-power comparators for an equivalent noise-temperature range of 75 to $30,000^{\circ} \mathrm{K}$ at accuracies of 0.2 to 1 percent.

Key Words: High frequency measurements, progress in radio measurements, attenuation measurements, impedance measurements, voltage measurements, field strength measurements, thermal noise measurements, phase measurements.

The conference on precision electromagnetic measurements, H. M. Altschuler, Proc. IEEE 55, No. 6, 782 (June 1967). The character of the biennial Conference on Precision Electromagnetic Measurements (CPEM) is described. The scope of the Conference is compared with that of the special issue of the Proceedings of the IEEE on Measurements. Some of CPEM's history is recounted and its increasing international coverage is noted. It is concluded that the challenge to CPEM grows with the expansion of the fields it covers.

Key Words: Conference, measurements, precision measurements, electromagnetic measurements, conference on precision electromagnetic measurements.

The nature of measurement, A. G. McNish, Book, Handbook of Industrial Metrology, Chapt. 1, pp. 2-12 (Prentice-Hall, Inc., Englewood Cliffs, N.J., 1967).

General principles for measurement. Accuracy and precision are discussed.

Key Words: Accuracy, measurement, precision.

U.S.A. National Committee Report, Fifteenth URSI General Assembly, Munich, September 1966: Commission 1, Radio Measurement Methods and Standards, Progress in Radio Measurement Methods and Standards, J. M. Richardson, Editor, Radio Science 1, No. 11, 1333-1342 (Nov. 1966).

Progress in radio measurement methods and standards within the United States during the Triennium 1963 through 1965 is reviewed for inclusion in the report of the U.S. National Committee of URSI to the 1966 General Assembly. Topics surveyed are high precision 
atomic frequency standards, high precision quartz frequency standards, scientific aspects of Universal and/or Atomic time and frequency transmissions, standards and measurements at $30 \mathrm{kc} / \mathrm{s}$ to $1 \mathrm{Gc} / \mathrm{s}$, standards and measurements at 1 to $300 \mathrm{Gc} / \mathrm{s}$, precision coaxial connectors, swept-frequency techniques, measurements of electromagnetic properties of materials, and laser standards and measurements. The topics are treated within the length limitation imposed by USNC/URSI.

Key Words: Radio measurement standards, radio measurement methods, frequency standards, time standards, electromagnetic properties of materials, coaxial connectors, microwaves, lasers.

Laser measurements of long distances, P. L. Bender, Proc. IEEE 55, No. 6, 1039-1045 (June 1967).

The extension of radio frequency techniques to the optical region of the spectrum has made possible many types of measurements which were not feasible before. One area in which important scientific contributions can be expected during the next few years is the use of lasers to measure long distances with high accuracy. Three types of distance measurements which have been discussed in the literature and which are now being investigated actively are: a) interferometric measurements over distances of up to hundreds of meters through evacuated or sealed-off tubes; b) measurements with modulated laser beams over distances of perhaps one to fifty kilometers with corrections made for the atmospheric index of refraction along the path; and c) range measurements to artificial satellites and to the moon using laser radar. Some of the possible geophysical and geodetic applications of such measurements will also be discussed.

Key Words: Laser measurements, radio frequency techniques, interferometric measurements, modulated laser beams, range measurements.

Low temperature (295-4. K) mechanical properties of selected copper alloys, R. P. Reed and R. Mikesell, J. Materials 2, No. 2, 370-392 (June 1967).

Fifteen copper alloys, including brasses, bronzes, and commercially pure coppers were tested to determine their tensile, notch tensile, Youngs modulus, and impact properties. Tests were performed at $295,195,76,20$, and $4{ }^{\circ} \mathrm{K}$. It was found that copper alloys, in general, have improved room low temperature properties as compared to room ambient temperature properties. The exception to this result is a cast $\mathrm{Ni}-\mathrm{Al}$ bronze alloy, which is brittle at low temperatures. In 9 alloys the yield and tensile strengths at $4{ }^{\circ} \mathrm{K}$ were less than at $20^{\circ} \mathrm{K}$. A discussion of this strength reduction at low temperatures is presented.

Key Words: Mechanical properties, low temperatures, copper, copper alloys.

Meteorology, essential of space age, A. G. McNish, George Washington University Mag. 1, No. 4, 10-14 (1965).

Understanding the physical world and the progress of civilization depends upon measurement.

Key Words: Metrology, standards, units, education.

Optical properties of germanium in the far ultraviolet, L. Marton and J. Toots, Phys. Rev. 160, No. 3, 602-606 (Aug. 15, 1967).

Reflectance measurements for Ge films in situ are reported for 16 wavelengths between 490 and $1610 \AA$, corresponding to photon energies of 25.2 and $7.7 \mathrm{eV}$. Measurements were taken after 3-min exposures to ambient pressures of $5 \times 10^{-7}$ Torr. Reflectance values at a number of angles of incidence were used to compute the optical constants: the refraction index $n$, the extinction coeffcient $k$, and the real and imaginary parts of the frequency-dependent dielectric constant $\epsilon(\omega)=\epsilon_{1}+i \epsilon_{2}$. Values are also presented for the characteristic electron energy-loss functions, i.e., the volume $\operatorname{loss},-\operatorname{Im} \epsilon^{-1}$, and the surface loss, $-\operatorname{Im}(\epsilon+1)^{-1}$. The quantity $-\mathrm{Im}^{-1}$ peaked at $16.1 \mathrm{eV}$ and had a half-width of $3.9 \mathrm{eV}$. Electron oscillator strengths, summed between 8 and $25 \mathrm{eV}$, gave a $h \omega_{p}$ value of $13.7 \mathrm{eV}$. The present data are in better agreement with the accepted plasma theory than are previous data. Some changes of optical characteristics caused by exposure to ambient pressures and air are presented.

Key Words: Characteristic electron energy loss, dielectric constant, far ultraviolet, germanium, optical constants, reflectance.

Properties of liquid hydrogen, R. J. Corruccini (Proc. Intern Inst. Refrigeration, June 9-11, 1965), Book, Liquid Hydrogen, pp 65-106 (Paris, France, 1965)

A review is presented of the physics of liquid hydrogen, and extensive extracts are provided of the available data on those of its physical properties that are important in technology.

Key Words: Cryogenic, hydrogen, liquid, low-temperature, properties.

U.S. Department of Commerce and the flammability of clothing fabric, A. F. Robertson, Bull. N.Y. Acad. Med. Second Series 43, No. 8, 706-710 (Aug. 1967).

The National Bureau of Standards has conducted studies of existing and modified test methods for measurement of flammable hazards associated with clothing fabrics. Recently, a cooperative program has been initiated with the Public Health Service to secure burn accident experience records which should yield information on the type of fabrics currently associated with clothing burn injuries. This program is just starting and it will be some years before valid information of the national picture becomes available. To date, however, there appears to be no technical evidence to show that a significant modification of the burn accident experience can be achieved without major changes in the flammable behavior of clothing fabrics. Thus, we hope industry will continue research on and development of permanently retardant-treated fabrics which will be economically, esthetically, and usefully acceptable to the public. It appears, in spite of the lack of direct evidence, that such fabrics will significantly reduce, but not eliminate, clothing fire injuries.

Key Words: Burn accident experience records, clothing fabrics, flammability, measurement of flammable hazards, permanently retardant-treated fabrics.

Perturbation theorems for waveguide junctions, with applications, D. M. Kerns and W. T. Grandy, Jr., IEEE Trans. Microwave Theory Tech. MTT-14, No. 2, 85-92 (Feb. 1966).

Perturbation theorems are derived in the context of a theory of waveguide junctions. These theorems express changes in impedance or admittance matrix elements, due to changes in a waveguide junction, in terms of integrals over products of perturbed and unperturbed basis fields associated with the junction and with its adjoint. Media involved are required only to be linear.

Concepts of first-order perturbation theory are discussed briefly, and the term "correct to the lowest order" is precisely defined. The need of explicit theorems telling when one may expect results actually correct to the lowest order is noted.

Two problems are solved approximately by the perturbation approach: (1) Reflection at the junction of rectangular waveguide with filleted waveguide of the same main dimensions, and (2) the effect of finite conductivity of both obstacle and waveguide wall for halfround inductive obstacles in rectangular waveguide.

Key Words: Correct to the lowest order, first-order perturbation theory, perturbation theorems, waveguide junctions.

Progress in measurement of electromagnetic properties of material, 1963 to mid-1966, H. E. Bussey (Proc. XV General Assembly of URSI, Munich, Germany, Sept. 5-15, 1966), Book, Progress in Radio Science 1963-1966, Part 1, pp. 265-289 (International Scientific Radio Union, Munich, Germany, 1966).

Progress on radio and microwave measurements of dielectric and magnetic properties of materials is reviewed mainly for the period 1963 to mid-1966. Important materials properties, theoretical analysis of circuits containing materials, and representative measurement methods are reviewed. In addition, some earlier basic work is referenced.

Key Words: Review, permittivity, dielectric constant, permeability, ferromagnetic resonance, bibliography. 
Development of an adhesive restorative material, R. L. Bowen (Proc. 2nd Workship, Adhesive Restorative Dental Materials, University of Virginia, Charlottesville, Va., Dec. 8-9, 1965), Book, Adhesive Restorative Dental Materials, No. 2, Chapt. 4, p. 225 (U.S. Public Health Service Publ. 1494, Supt. Doc. Government Printing Office, Washington, D.C. $20402 \$ 1.00,1966)$.

Recent findings, primarily from the literature, are reviewed on the subject of adhesive, restorative, dental materials, One mode of attack on the problem is described. In this, an inorganic-organic composite is used as the restorative material. The inorganic reinforcing fillers serve primarily to reduce the material's thermal expansion. A coupling agent improves the bonding between the phases. Bonding between the organic resin phase and the tooth surface is also improved by a coupling agent (surface-active comonomer).

Key Words: Adhesive, bonding, dental material bonding, resin, restorative.

Identification of dyes in paper by extraction and chromatographic analysis, M. R. Wallace, L. T. Milliken, and S. D. Toner, TAPPI 50, No. 9, 121A-124A (Sept. 1967).

A chromatographic procedure is described for the determination of a range of direct and acid dyes in dyed paper. It can be used for the identification of individual dyes in complex mixtures on unknown samples, and is simple and inexpensive enough to use in routine quality control testing of dyes and dyed paper.

$R_{f}$ values and visual appearances serve immediately to identify most of the paper dyes studied. Comparisons with known references give good estimates of the quantities of each dye present. Individ ual basic dyes could not be identified by this procedure, but the presence of a basic dye could be detected by its appearance in the solvent front. In a mixed furnish containing both acidic and basic dyes the acidic dyes could be determined without interference by the basic dyes. $R_{f}$ values for the principal characteristic bands of 26 dyes are listed.

Key Words: Chemical analysis, chemical tests, chromatography, dyes.

Modification of the fluoride activity electrode for microchemical analysis, R. A. Durst and J. K. Taylor, Anal. Chem. 39, No. 12, 1483-1485 (Oct. 1967).

A fluoride activity electrode has been modified for operation in the inverted position by converting the inner reference solution to a gel. Operation in this position makes possible the use of the singlecrystal fluoride-sensitive membrane as the sample "container" and permits the measurement of sample volumes as small as one drop $(50 \mu \mathrm{l})$. A caljbration curve is obtained for solutions containing $10^{-1} M$ to $10^{-6} M \mathrm{NaF}$ in $0.1 M \mathrm{KNO}_{3}$. The precision to which the fluoride concentration can be read from this calibration curve is calculated from the slope of the curve at the various concentrations and the standard deviation of the e.m.f. measurements. In the concentration range from $10^{-1} M$ to $10^{-3} M \mathrm{NaF}$, the calculated error is about $2 \%$. At the $10^{-5} \mathrm{M} \mathrm{NaF}$ level, 10 nanograms of fluoride can be determined with an error of approximately 0.7 nanogram. For sample volumes of $50 \mu 1$, the modified fluoride electrode was found to exhibit a usable response in the range from $10^{-1} M$ to $5 \times 10^{-6} M$ fluoride.

Key Words: Microchemical analysis; potentiometry; fluoride, analysis for; Specific Ion Electrode; fluoride electrode; electrochemical analysis.

Modified linear null-point potentiometry, R. A. Durst and J. K. Taylor, J. Chem. Educ. 39, No. 12, 1374-1379 (Oct. 1967).

A modification of the technique of precision null-point potentiometry has been developed in which a linear titration curve is obtained when the logarithm of the amount of coulometrically generated titrant is plotted against the concentration cell potential. The equivalence point is evaluated graphically and by computer techniques. The analyses of standard $0.1 \mathrm{ml}$ samples containing 0 to 13 $\mu \mathrm{g}$ of silver are discussed in detail. This technique was found to be applicable down to one nanoequivalent $(0.1 \mu \mathrm{g})$ of silver with an error of less than $5 \%$. Below this value, a positive deviation occurs due to the spontaneous dissolution of the silver indicator electrodes. The interference effects of several cations are also discussed.
Key Words: Null-point potentiometry, silver, microtitration, linear potentiometry, electroanalysis, potentiometry.

Dead weight piston gauge for pressures to 26 kilobars, D. P. Johnson and P. L. M. Heydemann, Rev. Sci. Instr. 38, No. 9, 12941300 (Sept. 1967).

The design and operation of a dead-weight piston gage for pressures to $26 \mathrm{kbar}$ is described. The gage is of the controlled clearance type. The diameter of the gage piston is $.2 \mathrm{~cm}$. It is loaded directly with up to $840 \mathrm{~kg}$ of weights. A volume of about $1 \mathrm{~cm}^{3}$ is provided inside the gage for the material under test. The use of this gage for transition pressure determinations is briefly discussed.

Key Words: High pressure, piston gage, transition pressure, pressure measurement.

Lou Costrell of NBS speaks out on the revolution in instrument packaging, L. Costrell, EEE 15, No. 8, 78-84 (Aug. 1967). The interchangeability problem posed by the advent of modular instrumentation has been alleviated by the development of a Standard Nuclear Module (NIM) system by the AEC Committee on Nuclear Instrument Modules. The Committee held its first meeting in March 1964. The completed specifications were issued in July 1964 and laboratory utilization and industry exhibit of the NIM system began in November 1964. Acceptance by the laboratories and by the nuclear instrument industry has been so rapid and so overwhelming that by September 1966 more than $70 \%$ of the total modular nuclear instruments produced in the U.S. were in the NIM system. The percentage today is even higher and the impact is world wide. Since all necessary components are available, other fields and other industries can readily adopt the system.

Key Words: Instrument, interchangeability, modules, nuclear, standard.

C. S. Peirce on benefit-cost analysis of scientific activity, W. E. Cushen, Operations Res. 15, No. 4, p. 641 (July-Aug. 1967). A very early paper on benefit-cost analysis of research projects was published in the Appendix to the Coast Survey's Annual Report 1876. A special issue of Operations Research, devoted to applications, is reprinting the original article, authored by Charles Sanders Peirce, who is better known as the father of pragmatism in American philosophical circles. The paper by Cushen serves to introduce the reprint and to paint a brief scene for its use and interpretation.

Key Words: Benefit-cost, research priorities, Peirce, philosophy, pragmatism, history, weights and measures.

Editor and translator, H. J. Oser, Book, Functional Analysis and Numerical Mathematics, by L. Collatz, Academic Press Inc., New York, N.Y., 1966.

Written primarily for graduate students in mathematics and physics, this book highlights the dramatic changes which have occurred in numerical mathematics during the past twenty years. The increased use of electronic computers and the tendency to develop more abstract methods are the primary factors in these rapid advances. The text is mainly concerned with those parts of functional analysis which have proven useful for numerical applications including Hilbert space theory, Banach spaces, metric spaces and pseudometric spaces, the theory of Frechet derivatives, and topological fixed-point theorems. Problems concerning iterative methods, differential and integral equations, and approximation theory are used to illustrate the applications.

Key Words: Banach spaces, Frechet derivative theory, functional analysis, Hilbert space theory, metric spaces, topological fixedpoint theorems.

Coping with multiple reflections in precise measurement of the speed of light with a microwave Michelson interferometer, D. M. Kerns (Proc. URSI Symp. Electromagnetic Wave Theory, Delft, The Netherlands, September 1965), Book, Electromagnetic Wave Theory, pp. 245-249 (Pergamon Press Inc., New York, N.Y., 1967).

A microwave version of the Michelson interferometer is currently being used for a precise determination of the speed of light, $c$. In 
preliminary experiments, multiple reflections between the antenna and the movable mirror of the system have been found to produce apparent variations in $c$, which, if uncorrected, would be an order of magnitude greater than tolerable. This paper establishes a theorem that should enable substantial elimination of errors due to multiple reflections. It is also shown that the four-arm junction in the arrangement - usually visualized as an ideal magic $T$-need have no special properties and in particular need have none of the ideal properties that distinguish an ideal magic $T$.

Key Words: Microwave Michelson interferometer, multiple reflections, speed of light.

Low-frequency electrical calibrations at the National Bureau of Standards, F. L. Hermach (Proc. 22nd Annual ISA Conf. and Exhibit, Chicago, Ill., Sept. 11-14, 1967), ISA Preprint M5-1MESTIND-67 (May 1967).

Charts are presented to show the present range and accuracy of NBS calibrations of standards of resistance, capacitance, inductance, voltage, current, from direct current through $50 \mathrm{kHz}$. The chains of measurements by which these and other calibrations are related to the basic NBS standards of voltage and resistance are also shown.

Key Words: Electrical calibrations, electrical standards, lowfrequency calibrations, low-frequency standards.

A note on the evaluation of interference photographs, J. R. Meyer-Arendt, Acta Histochem. 22, 58-61 (1965).

Interference patterns should be evaluated with respect to two parameters, namely the spatial displacement and the contrast of the fringes. The contrast permits the deduction of the degree of wavefront deformation in one of the two bundles brought to interference. A series of representative figures are shown in a plot.

Key Words: Interference photographs, photographs, wavefront deformation.

A simple, inexpensive wavefront shearing interferometer, J. B. Saunders, Appl. Opt. 6, No. 9, 1581-1583 (Sept. 1967).

An efficient wavefront shearing interferometer is easy to produce from two small right-angle prisms. A cube beam divider becomes such an interferometer when two if its faces are aluminized. Any chosen angle of shear is obtained by a simple rotation of one prism relative to the other. Chromatic compensation is achieved by sliding one prism relative to the other along their common face.

Key Words: Interferometer, wavefront shearing interferometer, prism interferometer.

Measurement standards, A. G. McNish, IEEE Student J. 4, No. 2, 24-31 (Mar. 1966).

All units of measurement, including the ampere of current and candela of light intensity-two base units included in the new International System of Units, are ultimately derived from four original prototype units - the meter of length, kilogram of mass, degree Kelvin of temperature, and second of time. To make all measurement units more effective tools, the standards that physically embody or define three of the prototypes-length, time, and temperature-have been changed in recent years.

Key Words: Length, mass, temperature, time, units of measurements.

The functions of Commission I of the International Scientific Radio Union, J. M. Richardson, Proc. IEEE 55, No. 6, 743-745 (June 1967).

Within the context of the objectives and characteristics of URSI, the functions of its Commission I on radio standards and measurements is given. It deals with the subject in the framework of careful survey, evaluation, and guidance of precision of standards and measurements; the attention is to the highest national levels of accuracy for the long term; the involvement is by people technically experienced and also in positions of enough responsibility to carry out the conclusions of the commission. The nature of its international and national activities, especially in the U.S., is given.
Key Words: Radio, standards, measurements, International Scientific Radio Union (URSI).

Ionosphere, T. E. VanZandt, Encyclopedia of Physics, Ed. R. M. Besancon, pp. 348-349 (Reinhold Publ. Co., New York, N.Y., 1966). The structure and physics of the ionosphere are briefly reviewed. The ionospheric regions are named. Then for each region are given: its height range, ionic composition, electron concentration, causes of ionization, and loss processes. Transport of ionization is mentioned. Sporadic $E$ and spread $F$ are described.

Key Words: Electron concentration, height range, ionic composition, ionosphere, ionospheric regions.

Mechanistic aspects of hearing, E. L. R. Corliss, J. Acoust. Soc. Am. 41, No. 6, 1500-1516 (June 1967).

The results of a number of apparently diverse experiments on human hearing can be summarized via a simple model. Two mechanisms are required: One element emits unit responses whose number is proportional to the instantaneous amplitude of a sound. The other is a selector mechanism, analogous to a resonant circuit, that integrates the responses. Correspondingly, just two parameters are involved: the threshold of hearing and the " $Q$ " of the selector mechanism. The system of equations representing the model makes it possible to derive the necessary parameters from the results of a number of different types of experiments. The theory of the selector mechanism is based upon a recent study of the limits of performance of a system capable of storing oscillatory energy reversibly, but the remainder of the theoretical description makes use of ordinary communication theory.

The discrimination ability of the normal ear is shown to be proportional to the one-fourth power of the level above threshold, and to relate closely to the sensation of loudness. Many features of the behavior of normal and impaired ears can be predicted by application of familiar network theory to the parameters derived from the model. The properties of the model may be used as criteria in the choice of experiments to develop explicit data on the way the ear performs its function.

Key Words: Hearing, mechanistic model of hearing, communication theory, resolving power of the ear, ear behavior, auditory perception, auditory analysis.

Second breakdown -A comprehensive review, H. A. Schafft, Proc. IEEE 55, No. 8, 1272-1288 (Aug. 1967).

This paper is a comprehensive review of the published literature dealing with the phenomenon of second breakdown in semiconductor devices and the problems it creates in the design, fabrication, testing, and application of transistors.

Key Words: Review, semiconductor devices, transistors, diodes, second breakdown, thermal breakdown, transistor reliability, circuit reliability, failure modes, failure mechanisms.

Superconductive properties of ceramic mixed titanates, J. F. Schooley, H. P. R. Frederikse, W. R. Hosler, and E. R. Pfeiffer, Phys. Rev. 159, No. 2, 301-305 (July 10, 1967).

The superconducting transition temperatures of a series of mixed barium-strontium and calcium-strontium titanate ceramic specimens have been determined. For several of these samples the low-field magnetization has also been investigated. The results are compared with those obtained from single-crystal $\mathrm{SrTiO}_{3}$.

Key Words: Barium, ceramic mixed titanates, low field magnetization, strontium, superconducting transition temperatures, superconductive properties.

The radiative band pinch effect and temperature dependence of radiative recombination in GaAs, N. N. Winogradoff, K. Owen, and R. M. Curnutt, Int. J. Electronics 22, No. 3, 229-233 (Mar. 29, 1967).

Localized heating of $\mathrm{GaAs}$ by intense ruby laser flashes cause a reduction or "pinching" of the band gap in the illuminated region. The increase in wavelength of the recombination radiation from this region permits the study of the temperature dependence of the internal quantum efficiency without absorption in the colder, wide band gap regions. 
The results show that the internal quantum efficiency decrease with an increase in temperature.

Key Words: GaAs, radiative recombination, temperature dependence, quantum efficiency, ruby laser.

Another method of synthesizing nonuniformly spaced antenna arrays, M. T. Ma, Trans. IEEE Ant. Prop. AP-13, No. 5, 833-834 (Sept. 1965).

A formulation for synthesizing an optimum nonuniformly spaced but symmetrical array by adjusting both the amplitude excitations and element spacings is given. This is accomplished by applying Haar's theorem which is known in a branch of mathematics. It is shown that the solution obtained according to the method proposed here is optimum in the senses that, with respect to a chosen set of element spacings, 1) the maximum deviation between the synthesized and desired patterns is minimized, 2) the side lobes can be made equal and their level minimum for a specified beamwidth, 3) the side lobe level and beamwidth are not mutually constrained so that a solution better than the Dolph-Chebyshev array is possible, 4) a minimum number of elements required to synthesize a desired pattern can be determined, and 5) the solution is unique.

Key Words: Amplitude excitations, antenna arrays, element spacings, nonuniformly spaced antenna arrays, synthesizing nonuniformly spaced antenna arrays.

Antennas, H. V. Cottony, Encyclopedia of Physics, Ed. R. M. Besancon, pp. 25-28 (Reinhold Publ. Co., New York, N.Y., 1966). The functions and properties of antennas are outlined in a 1500 word article for use in an encyclopedia. The presentation is presented from a view point that an antenna is a network designed to facilitate the transfer of information energy from circuits to space and reverse. The relationship between an antenna and the contiguous electronic circuit is determined and fully described by the terminal impedances of the circuit and antenna. Because of the three-dimensional nature of propagating medium and the nature of electromagnetic wave, the performance of an antenna as a radiator is more complex. For full description, it requires the specifications of its radiation pattern in space, and the polarization of the radiated electromagnetic wave. Six illustrations of different types of antennas are presented.

Key Words: Antennas, circuits, contiguous electronic circuit, electronic circuit, information energy, terminal impedance.

The development of an International atomic time sacle, J. A. Barnes, Proc. IEEE 55, No. 6, 822-826 (June 1967).

The paper reviews briefly the methods of generating atomic time and the errors inherent in the resulting scales. An atomic clock consists of an atomic frequency standard and an "integrator" to accumulate the phase of the signal. Because of noise perturbing the instantaneous frequency, an ensemble of identical atomic clocks will show a distribution of (epoch) times which is unbounded as the system evolves in time. The recognition of this problem has important consequences in national and international coordination of time scales and the construction of average atomic time scales. Also of significance is the not completely resolved question of weighting of individual standards in the construction of average time scales. In spite of these difficulties it is pointed out that through coordination and proper data handling, most of the advantages of astronomical time scales can be realized by atomic time scales. A statement of some of the problems facing any attempts at coordination is presented without any suggested solution.

Key Words: Atomic time, coordination, atomic frequency standards.

\section{Other NBS Publications}

J. Res. NBS 72A (Phys. and Chem.), No. 1 (Jan.-Feb. 1968), $\$ 1.00$.

Reactions of uranium with the platinide elements. I. The uraniumruthenium system. J. J. Park.

Reactions of uranium and the platinide elements. II. The uraniumrhodium system. J. J. Park.

Reactions of uranium and the platinide elements. III. The uraniumiridium system. J. J. Park and L. R. Mullen.
Phase relations between palladium oxide and the rare earth sesquioxides in air. C. L. McDaniel and S. J. Schneider.

Preparation and purification of some oxidation products of perylene. A. J. Fatiadi.

Electron spin resonance spectra of polymer radicals in aqueous solution. R. E. Florin, F. Sicilio, and L. A. Wall.

A mass spectrometric study of the $\mathrm{BeO}-\mathrm{BeF}_{2}$ system at high temperatures. J. Efimenko.

Laser induced Raman spectra of some tungstates and molybdates. R. K. Khanna, W. S. Brower, B. R. Guscott, and E. R. Lippincott. Valence-only correlation in $\mathrm{LiH}$ and $\mathrm{BeH}^{+}$. W. A. Sanders and M. Krauss.

Thermalization by elastic collisions: positronium in a rare gas moderator. W. C. Sauder.

Density fluctuations in fluids having an internal degree of freedom. R. D. Mountain.

J. Res. NBS $71 B$ (Math. and Math. Phys.), No. 4 (Oct.-Dec. 1967), 75 cents.

Calibration designs based on solutions to the tournament problem. R. C. Bose and J. M. Cameron.

Bounds for the solutions of second-order linear difference equations. F. W. J. Olver.

Notes on automorphic functions: An entire automorphic form of positive dimension is zero. M. I. Knopp.

Solving equations exactly. M. Newman.

A system of equations having no nontrivial solutions. H. Gupta.

Remarks on cut-sets. J. W. Grossman.

A pseudo primal-dual integer programming algorithm. F. Glover. Properties of a useful biorthogonal system. L. V. Spencer and P. Flusser.

On even matroids. W. T. Tutte.

Matrices of class $J_{2}$. J. S. Maybee.

Partially isometric matrices. J. Z. Hearon.

Symmetrizable generalized inverses of symmetrizable matrices. J. Z. Hearon.

Optimum branchings. J. Edmonds.

Systems of distinct representatives (SDR) and linear algebra J. Edmonds.

Bounds for the number of generators of a finite group. M. Newman.

Analytical Mass Spectrometry Section: Summary of activities July 1966 to June 1967, Ed. W. R. Shields, Tech. Note 426, (Sept. $15,1967), 40$ cents.

Electrochemical Analysis Section: Summary of activities July 1966 to June 1967, Ed. R. G. Bates, Tech. Note 423 (Oct. 1967), 50 cents Loading factors and FDM-FM system performance calculations, E. F. Florman, Tech. Note 100-A (Sept. 1967), 20 cents. Supplement to Appendix C of Tech. Note 100.

Microchemical Analysis Section: Summary of activities July 1966 to June 1967, Ed. J. K. Taylor, Tech. Note 425 (Oct. 1967), 50 cents.

1967 Technical Highlights of the National Bureau of Standards, Annual Report, Fiscal Year 1967, Misc. Publ. 293 (Nov. 1967), 55 cents.

Photonuclear data index, January 1965 through April 1967, Misc. Publ. 277, Supplement 1 (Oct. 1967), 45 cents.

Selected values of electric dipole moments for molecules in the gas phase, R. D. Nelson, Jr., D. R. Lide, Jr., and A. A. Maryott, NSRDS-NBS10 (Sept. 1, 1967), 40 cents. (Supersedes the data on dipole moments included in NBS Circ. 537).

Tables of molecular vibrational frequencies Part 2, T. Shimanouchi, NSRDS-NBS11 (Oct. 1967), 30 cents.

A comparison between solar X-ray emission and VLF sudden phase anomalies, C. J. Chilton, J. P. Conner, and F. K. Steele, Proc. IEEE 53, No. 12, 2018-2026 (Dec. 1965).

A novel, facile preparation of $1,1^{\prime}$-bipyrene, A. J. Fatiadi, J. Org. Chem. 32, 2903-2904 (Sept. 1967).

Aggregation in matrix models of resource flows. II. Boolean relation matrix methods, D. R. Rosenblatt, Am. Stat. 21, No. 3, 32-37 (June 1967)

Angular scattering law for the moon at 6 meter wavelength, W. K. Klemperer, J. Geophys. Res. Letter 70, No. 15, 3798-3800 (Aug. 1965). 
Application of the Fock expansion to doubly excited states of the helium atom, J. H. Macek, Phys. Rev. 160, No. 1, 170-174 (Aug. 5, 1967).

Brief report of the XV URSI General Assembly, Commission I, on the status of international intercomparisons of high frequency and microwave electrical quantities, M. C. Selby (Proc. XV General Assembly of URSI, Munich, Germany, Sept. 5-15, 1966), Book, Progress in Radio Science 1963-1966, Part 1, pp. 113-116 (International Scientific Radio Union, Munich, Germany, Sept. 1966).

Characteristic energy losses of $8 \mathrm{KeV}$ electrons in liquid $\mathrm{In}-\mathrm{Al}$ and In-Bi alloys, C. J. Powell, Advan. Phys. 16, 203 (1967).

Characteristics of a slotted-sphere antenna immersed in a compressible plasma. J. R. Wait (Proc. Conf. Microwave Behaviour of Ferrimagnetics and Plasmas), Conf. Publ. No. 13, pp. 1-4 (Inst. Electrical Engineers, London, England, 1965).

Comment on "paramagnetic resonance of alkyl nitroxides", R. E. Florin, J. Chem. Phys. 47, No. 1, 345-346 (July 1, 1967).

Conformation of polystyrene adsorbed on liquid mercury, R. R. Stromberg and L. E. Smith, J. Phys. Chem. 71, No. 8, 2470-2474. (July 1967).

Cross section for $\mathrm{Na}\left({ }^{2} \mathrm{P}_{1 / 2},{ }^{2} \mathrm{P}_{3 / 2}\right)$ intramultiplet transactions induced by collisions with the hydrogen atoms, R. N. Zare and P. L. Bender, Proc. Am. Phys. Soc. Meeting, Los Angeles, Calif. 10, 1183 (American Physical Society, New York, N.Y., 1965).

Cyclotron harmonic emission from the abnormal negative glow plasma, K. B. Persson, D. A. Uhlenbrock, and E. G. Johnson, Bull. Am. Phys. Soc. 12, Series II, No. 5, 756 (May 1967).

Definitions of $v, i, Z, Y, a, b, \Gamma$, and $S$, D. M. Kerns, Proc. IEEE 55, No. 6, 892-900 (June 1967).

Dissociative ionization of $\mathrm{H}_{2}$ and $\mathrm{D}_{2}$, L. J. Kieffer and G. H. Dunn, Phys. Rev. 158, No. 1, 61-65 (June 5, 1967).

Effects of impurities on the production of oxygen atoms by a microwave discharge, R. L. Brown, J. Phys. Chem. 71, No. 8, 2492-2495 (1967).

Electronic computer applications in urban transportation planning, R. E. Schofer and F. F. Goodyear (Proc. 22nd Natl. Conf. Association for Computing Machinery, Washington, D.C., Aug. 29-31, 1967), A. C. M. Publ. P-67, pp. 247-253 (Thompson Book Co., Washington, D.C., July 1967).

Equations of motion in nonequilibrium statistical mechanics. II. Energy transport, B. Robertson, Phys. Rev. 160, No. 1, 175183 (Aug. 5, 1967).

Equivalence between two formalisms of plasma fluctuations, J. Weinstock, Phys. Fluids 9, No. 3, 621-622 (Mar. 1966).

Excited species and their contribution to $\mathrm{NO}(\beta, \gamma)$ fluorescence in the photodissociation of $\mathrm{N}_{2} \mathrm{O}$, I. Okabe, J. Chem. Phys. 47, No. 1, 101-109 (July 1, 1967).

Experimental ermination of transition probabilities and Stark widths of S I and S II lines, J. M. Bridges and W. L. Wiese, Phys. Rev. 159, No. 1, 31-38 (July 5, 1967).

$\mathrm{F}^{19}$ relaxation in AFM KMnF 3 , P. T. Parrish, A. C. Daniel, and R. J. Mahler, Bull. Am. Phys. Soc. 12, Series II, No. 3, 284 (Mar. 1967).

Hall mobility in $\mathrm{SrTiO}_{3}, \mathrm{H}$. P. R. Frederikse and W. R. Hosler, Phys. Rev. 161, No. 3, 822-827 (Sept. 15, 1967).

Insertion of methylene into alkanes, M. L. Halberstadt and J. R. McNesby, J. Am. Chem. Soc. 89, No. 14, 3417-3420 (1967).

Interpretation of cyclotron resonance line shapes in slightly ionized gases, F. C. Fehsenfeld. L. R. Megill, and L. K. Droppleman, J. Chem. Phys. 43, 3618-3624 (Nov

Interpretation of de Grinberg's experiments on lateral surface fringes in sodinn hlorid H. P Ttech, Phys. Stat. Solidi 20, K41-K43 (796-

Lifetimes of some $4 p$ levels in argon I, J. Z. Klose, J. Opt. Soc. Am. 57, No. 10, 1242-1244 (Oct. 1967).

Linear measurements, T. R. Young, Book, Handbook of Industrial Metrology, Chapt. 3, pp. 55-81 (Prentice-Hall, Inc., Englewood Cliffs, N. J., 1967).

Liquid-vapor equilibrium in the system helium-methane, C. K. Heck and M. J. Hiza, AIChE. J. 13, No. 3, 593-599 (May 1967).

Localized-induction concept on a curved vortex and motion of an elliptic vortex ring, R. J. Arms and F. R. Hama, Phys. Fluids 8, No. .. 53- 559 (Apr. . .5)

Matrix-isolation study of the reaction of carbon atoms with chlorine. The electronic and vibrational spectra of the free radical $\mathrm{CCl}_{2}$, D. E. Milligan and M. E. Jacox, J. Chem. Phys. 47, No. 2, 703-707 (July 15, 1967).
Measurement of density and specific gravity, J. K. Taylor, Book, Treatise on Analytical Chemistry, Ed. I. M. Kolthoff, P. J. Elving, and E. B. Sandell, Part 1, Theory and Practice, 7, Chapt. 81, 4561-4610 (Interscience Publ., New York, N.Y., 1967).

Measurements of Stark profiles of C II and Ca II lines, J. R. Roberts and K. L. Eckerle, Phys. Rev. 159, No. 1, 104-107 (July 5, 1967).

Nature of ionic deformations in crystals; application to an analysis of the magnetic properties of the alkalihalide and alkaline-earth oxide crystals, A. R. Ruffa, Phys. Rev. 159, No. 3, 742-754 (July 15, 1967).

Non-linear diffusion with recombination in electron beam excited plasma, E. R. Mosburg, Jr. and M. S. Lojko, Phys. Fluid Res. Notes 9, No. 4, 824-826 (Apr. 1966).

Note on paritions modulo 5, M. Newman, Math. Compt. 21, No. 99, 481-482 (July 1967).

Nuclear magnetic acoustic resonance in $\mathrm{KTaO}_{3}$, R. W. Mebs, L. H. Bennett, and J. R. Leibowitz, Physics Letters 24.A, No. 12, 665-666 (June 5, 1967)

On the explanation of the so-called CN laser, D. R. Lide, Jr. and A. G. Maki, Appl. Phys. Letters 11, No. 2, 62-64 (July 15, 1967).

On the structure of pyrazole, A. D. Mighell and C. W. Reimann, J. Phys. Chem. 71, No. 7, 2375-2376 (June 1967).

Optical and magnetic measurements on single crystals of copper(II)doped tris(phenanthroline)zinc(II) nitrate dihydrate, G. F. Kokoszka, C. W. Reimann, H. C. Allen, Jr., and G. Gordon, Inorg. Chem. 6, No. 9, 1657-1661 (1967).

Polymerization and pyrolysis of poly-1,2-dihydronaphthalene, L. A Wall, L. J. Fetters, and S. Straus, Polymer Letters 5, No. 8, 721-733 (Aug. 1967).

Positive and negative self-surface ionization of tungsten and rhenium, M. D. Scheer and J. Fine, J. Chem. Phys. 46, No. 10, 39984003 (May 15, 1967).

Proof of a permanental inequality, R. A. Brualdi and M. Newman, Quart. J. Math. 17, No. 67, 234-238 (Sept. 1966).

Remarks for XV URSI General Assembly session on progress at $f \leqslant 1 \mathrm{GHz}$, M. C. Selby (Proc. XV General Assembly of URSI, Munich, Germany, Sept. 5-15, 1966), Book, Progress in Radio Science 1963-1966, Part 1, pp. 157-162 (International Scientific Radio Union, Munich, Germany, Sept. 1966).

Reply by A. G. McNish, Phys. Today 19, No. 4, 15-16 (Apr. 1966).

Reply to "Comments on Reed letter, by H. M. Otte," R. P. Reed, Acta. Met. 15, No. 6, 1082-1083 (June 1967).

Robust estimation of location, E. L. Crow and M. M. Siddiqui, J. Am. Stat. Assoc. 62, No. 318, 353-389 (June 1967).

Scanning the issue, R. W. Beatty and B. O. Weinschel, Proc. IEEE 55, No. 6, 737-740 (June 1967).

Scheduling a vehicle between an origin and a destination to maximize traveler satisfaction, D. Young (Proc. 22nd Natl. Conf. Association for Computing Machinery, Washington, D.C., Aug. 29-31, 1967), A. C. M. Publ. P-67, pp. 233-245 (Thompson Book Co., Washington, D.C., July 1967).

Single- and double-quantum photodetachment of negative ions, E. J. Robinson and S. Geltman, Phys. Rev. 153, No. 1, 4-8 (Jan. 1967).

Some radio-physical considerations in studies of the fine scale structure of the atmosphere, B. R. Bean and B. D. Warner, Proc. Intern. Conf. Fine Scale Structure of the Atmosphere, Moscow, USSR, June 1965, pp. 215-224 (1965).

Spectroscopic study of the vacuum-ultraviolet photolysis of matrixisolated $\mathrm{HCN}$ and halogen cyanides. Infrared spectra of the species CN and XNC, D. E. Milligan and M. E. Jacox, J. Chem. Phys. 47, No. 1, 278-285 (July 1, 1967).

Sporadic- $E$ ionization, E. K. Smith, Annual Suppl. Encyclopedic Dictionary of Physics, Ed. J. Therolis, Suppl. I, 239-331 (Pergamon Press, Inc., New York, N.Y., 1966).

Suppressed and accelerated spin-lattice relaxation, R. L. Peterson, Phys. Rev. 159, No. 2, 227-233 (July 10, 1967).

Surface self-diffusion of nickel and platinum, A. J. Melmed, J. Appl. Phys. 38, No. 4, 1885-1892 (Mar. 1967).

Synchrotron radiation measurements near the magnetic equator, G. R. Ochs, Book, Radiation Trapped in the Earth's Magnetic Field, Ed. B. McCormac, pp. 703-713 (D. Riedel Publ. Co., Dordrecht, The Netherlands, 1966).

Temperature dependence of the nuclear quadrupole resonance frequency of ${ }^{35} \mathrm{Cl}$ in $\mathrm{KClO}_{3}$ between 12 and $90{ }^{\circ} \mathrm{K}, \mathrm{D}$. B. Utton, J. Chem. Phys. 4.7. No. 2, 371-373 (July 15, 1967).

The application a partial correlation analyses to the study of the occurrene? 
Conf. Spread $F$ and Its Effects Upon Radiowave Propagation and Communication, Copenhagen, Denmark, Aug. 1964), AGARD. ograph 95, pp. 167-188 (W. and J. Mackay, London, England, 1966).

The aurora, A. G. McNish, Proc. NATO Advanced Study Institute, Bad Homburg, Germany, July 22-Aug. 2, 1963, Ed. D. S. Bleil, pp. 77-93 (Plenum Press, Inc., New York, N.Y., 1964).

The crystal and molecular structure of tetrakispyrazole-nickel chloride, $\mathrm{Ni}\left(\mathrm{C}_{3} \mathrm{H}_{4} \mathrm{~N}_{2}\right)_{4} \mathrm{Cl}_{2}$, C. W. Reimann, A. D. Mighell, and F. A. Mauer, Acta Cryst. 23, Part 1, 135-141 (July 1967).

The determination of bound styrene in insoluble emulsion polymerized styrene-butadiene copolymers, M. A. Post, J. Appl. Chem. 17, 203-208 (July 1967).

The effect of spread $F$ on the propagation of radiowaves near the equator, K. Davies and A. F. Barghausen (Proc. AGARD Conf. Spread $F$ and Its Effects Upon Radiowave Propagation and Communication, Copenhagen, Denmark, Aug. 1964), AGARD ograph 95, pp. 437-466 (W. and J. Mackay, London, England, 1966).

The energies of $\mathrm{N}^{+}$from the dissociative ionization of $\mathrm{N}_{2}$ (Abstract), L. J. Kieffer and R. J. Van Brunt (Proc. 18th Annual Gaseous Electronics Conf., Minneapolis, Minn., Oct. 21, 1965), Bull. Am. Phys. Soc. 11, No. 4, 499 (1966).

The role of the NBS Radio Standards Laboratory, H. M. Altschuler, Proc. IEEE 55, No. 6, 778-781 (June 1967).

The system $\mathrm{Y}_{2} \mathrm{O}_{3}-\mathrm{V}_{2} \mathrm{O}_{5}$, E. M. Levin, J. Am. Ceram. Soc. 50, No. 7, 381-382 (July 1967).
The thermal decomposition of poly-3,3,3,-tri-fluoropropene made at high pressure, S. Straus and D. W. Brown (Proc. 152nd American Chemical Society Meeting, New York, N.Y., Sept. 13, 1966), Polymer Preprint 7, No. 2, 1128-1132 (Sept. 1966).

The unperturbed dimension temperature coefficients of some fluorine-containing polymers, H. Yu (Proc. 152nd American Chemical Society Meeting, New York, N.Y., Sept. 13, 1966), Polymer Preprint 7, No. 2, 1143-1145 (Sept. 1966).

The use of multiple antennas in studies of absorption at conjugate points, H. J. A. Chivers and J. K. Hargreaves, Proc. Symp. High Latitude Particles and the Ionosphere, Alpbach, Austria, 1964, pp. 257-264 (Academic Press, Inc., New York, N.Y., 1965).

Vacuum-ultraviolet photolysis of acetylene in inert matrices. Spectroscopic study of the species $\mathrm{C}_{2}$, D. E. Milligan, M. E. Jacox, and L. Abouaf-Marguin, J. Chem. Phys. 46, No. 12, 4562-4570 (June 15, 1967).

Variational calculations for quartet states of three-electron atomic systems, S. Geltman and E. Holein, Phys. Rev. 153, No. 1, 81 (1967).

*Publications for which a price is indicated are available by purchase from the Superintendent of Documents, U.S. Government Printing Office, Washington, D.C. 20402 (foreign postage, onefourth additional). The NBS nonperiodical series are also available from the Clearinghouse for Federal Scientific and Technical Information, Springfield, Va. 22151. Reprints from outside journals and the NBS Journal of Research may often be obtained directly from the authors. 